\title{
Monetary and non-monetary incentives in real-effort tournaments*
}

\author{
Nisvan Erkal, ${ }^{\dagger}$ Lata Gangadharan, ${ }^{\ddagger}$ and Boon Han $\mathrm{Koh}^{\S}$
}

\author{
October 2017
}

\begin{abstract}
Results from laboratory experiments using real-effort tasks provide mixed evidence on the relationship between monetary incentives and effort provision. To examine this issue, we design three experiments where subjects participate in two-player real-effort tournaments with two prizes. Experiment 1 shows that subjects exert high effort even if there are no monetary incentives, suggesting that non-monetary incentives are contributing to their effort choices. Moreover, increasing monetary incentives does not result in higher effort provision. Experiment 2 shows that the impact of non-monetary incentives can be reduced by providing subjects with the option of leaving the laboratory early, using an incentivized timeout button, or working on an incentivized alternative activity. Experiment 3 revisits the relationship between monetary incentives and effort provision using the insights from Experiment 2. Using a design with an incentivized alternative activity, we show that participants increase effort in response to monetary incentives. Taken together, the findings from the three experiments suggest that results from real-effort tasks require a careful evaluation and interpretation of the motivations underlying the observed performance.
\end{abstract}

Keywords: Real-effort tasks; Laboratory experiments; Contests; Non-monetary incentives; Monetary incentives

JEL Classification: C90; D01; J30

\footnotetext{
* We would like to thank Tim Cason, Cary Deck, Nick Feltovich, Simon Gächter, Phil Grossman, Lingbo Huang, Guy Mayraz, Daniele Nosenzo, Jörg Oechssler, Roman Sheremeta, Bob Slonim, Chris Starmer, Marie Claire Villeval, Tom Wilkening, the Associate Editor, three anonymous reviewers, participants at the $10^{\text {th }}$ Annual Australia New Zealand Workshop on Experimental Economics (ANZWEE), the 2016 Economics and Biology of Contests Conference (EBCC), the 2016 North American Meetings of the Economic Science Association (ESA), the 2017 CBESS-CeDEx-CREED (CCC) Meeting, and seminar participants at the University of Melbourne for their comments and feedback. We thank the Australian Research Council (DP1094676) for their financial support. ${ }^{\dagger}$ Corresponding author. Department of Economics, University of Melbourne, VIC 3010, Australia. Email: n.erkal@unimelb.edu.au.

₹ Department of Economics, Monash University, VIC 3800, Australia. Email: lata.gangadharan@monash.edu.

$\S$ Department of Economics, University of Melbourne, VIC 3010, Australia. Email: boonhan.koh@unimelb.edu.au.
} 


\section{Introduction}

The impact of incentives on the supply of effort is a central question in economics. In recent years, economists have been increasingly relying on laboratory experiments, especially experiments with real-effort tasks, to study this question. Real-effort tasks require experimental participants to exert actual physical or mental effort to earn money. ${ }^{1}$ They are seen as a better representation of how people earn their income in the real world in comparison to the alternative 'stated effort' designs, where subjects are given information on the costs and benefits of different effort options and are asked to state the level of effort they would like to exert (see, e.g., Charness and Kuhn, 2011).

While the use of real-effort tasks may contribute to the external validity of experimental results, it may also come at a cost of loss of control over incentives. ${ }^{2}$ The main concern voiced in the literature is that in real-effort tasks, researchers cannot observe the cost of effort which differs across subjects. This makes it challenging to compare the behavior of subjects against theoretical benchmarks derived from assumed cost-of-effort functions. ${ }^{3}$ In contrast, in statedeffort experiments, the parameters guiding the optimization problem of subjects are clear.

Not knowing the (monetary) marginal cost of effort is not the only reason for loss of control in real-effort tasks. The introduction of a real-effort task also means that non-monetary incentives (such as task enjoyment) can play a larger role in the determination of effort. Hence, if the goal of the researcher is to measure the impact of monetary incentives on effort provision,

\footnotetext{
${ }^{1}$ Examples include adjusting sliders on the screen (Gill and Prowse, 2012), pressing keys (Berger and Pope, 2011), counting zeroes (Abeler et al., 2011), typing paragraphs (Dickinson, 1999), cracking walnuts (Fahr and Irlenbusch, 2000), stuffing letters into envelopes (Konow, 2000; Falk and Ichino, 2006; Carpenter, Matthews, and Schirm, 2010), encrypting words (Erkal, Gangadharan, and Nikiforakis, 2011), adding numbers (Niederle and Vesterlund, 2007), solving mazes (Gneezy, Niederle, and Rustichini, 2003), picking virtual apples in a basket (Eriksson, Mao, and Villeval, 2017), and solving crossword puzzles (Kraut et al., 2005).

${ }^{2}$ This is concerning since the key advantage of using experimental methods is the ability to control for extraneous confounding influences and, hence, the ability to make direct inferences relating to causality.

${ }^{3}$ For this reason, recently, some researchers (e.g., DellaVigna et al., 2016) study how subjects' cost of effort in real-effort tasks can be estimated.
} 
clearly this becomes more challenging. The presence of non-monetary incentives may make it difficult to identify the impact of monetary incentives. This may be the reason why results from experiments using real-effort tasks provide mixed evidence on the relationship between monetary incentives and effort provision. For example, in their survey article, Camerer and Hogarth (1999) report that in some real-effort studies subjects respond to monetary incentives, while in others incentives fail to provoke a response or may even backfire (see also Jenkins et al., 1998; Gneezy and Rustichini, 2000; Pokorny, 2008; Ariely et al., 2009; Araujo et al., 2016; DellaVigna and Pope, forthcoming).

This evidence suggests that it is important to have a systematic exploration of the impact of monetary and non-monetary incentives in order to determine under what circumstances they increase effort. The goal of this paper is to identify the impact of monetary incentives on effort provision by reducing the impact of non-monetary incentives. We report findings from three related experiments designed to study effort provision within a real-effort contest setup. Contests are used in many economic, political, and social environments, e.g., competition for bonuses and promotions within firms, patent races, lobbying for government contracts, elections, political conflicts, and sports. Our approach is based on the conjecture that, in addition to money, the following factors may contribute to participants' effort choices in realeffort contests: (i) task enjoyment; (ii) the desire to do what is expected of one and/or something productive/useful for others (which results in the experimenter demand effect); and (iii) competitiveness.

Experiment 1 presents the 'puzzle' we aim to address in this paper. Subjects participate in two-player tournaments with two prizes. We eliminate the impact of monetary incentives on behavior by setting the prizes equal to each other in the baseline treatment. We show that effort provision in this treatment is not significantly different from effort provision in two other 
treatments with low and high monetary incentives. Hence, non-monetary incentives by themselves are sufficient to motivate subjects to exert significant levels of effort in real-effort tasks. Moreover, providing monetary incentives does not have an impact on effort provision. This result is in line with other findings in the literature which document that behavior in realeffort tasks is relatively insensitive to changes in monetary incentives (e.g., Camerer and Hogarth, 1999; Araujo et al., 2016).

In Experiment 2, we design treatments to reduce the impact that the non-monetary incentives mentioned above have on effort. Using a simple framework, we explain that this can be done either directly by reducing the benefit subjects receive from task enjoyment, etc. (e.g., by picking a task that is likely to be less enjoyable), or indirectly by increasing the cost of working on the task. We consider two treatments aimed at increasing the opportunity cost of effort (by allowing participants to leave early and by providing them with a small payment for taking a timeout), and a third treatment with an incentivized alternative activity which aims to increase the opportunity cost of effort at the same time it decreases the non-monetary benefits subjects may receive from performing the real-effort task. We show that participation and effort in the real-effort task are significantly lower in all three treatments as compared to the baseline treatment from Experiment 1. Moreover, introducing an incentivized alternative activity that pays a piece rate is the most effective way of reducing the impact of non-monetary incentives, while allowing subjects to leave early is the least effective.

In Experiment 3, we again examine the response of agents to changes in monetary incentives. However, this time we use the design with an incentivized alternative activity from Experiment 2. We find that, in contrast to our results from Experiment 1, participants increase effort monotonically in response to monetary incentives. Hence, our results reveal that, with appropriate modifications to the way real-effort tasks are implemented in the laboratory, it is 
possible for the experimenter to observe changes in effort provision as the level of monetary incentives is varied.

In general, the findings from our three experiments highlight that understanding the role of incentives in real-effort tasks has important implications. We provide a framework that allows the researcher to mitigate the impact of non-monetary incentives in real-effort experiments. Beyond studying the role of monetary incentives on effort, doing this can be important if the researcher wants to examine how the process of earning one's income affects the decisions in later stages of the experiment. If non-monetary incentives (e.g., experimenter demand effect or task curiosity) play a bigger role in determining effort choices, then subjects' behavior in the later stage may be driven by their response to these incentives rather than differences in income levels. In this case, failing to acknowledge the role that non-monetary incentives play on effort provision in the first stage may result in a misidentification of the causal effect.

The rest of the paper proceeds as follows. In the next section, we review the related literature and discuss our contributions to it. In Sections 3 to 5, we present the design and results of Experiments 1, 2, and 3, respectively. We conclude in Section 6 with a discussion of the implications of our findings.

\section{Related Literature}

We build on and contribute to different strands of the literature. Our first contribution is to the literature on the impact of incentives. We examine how experimental economists can study the role of incentives using real-effort experiments in the laboratory. A central principle of economic analysis is that people respond to incentives. Hence, economists see incentives as a powerful tool for explaining and altering individual behavior. When it comes to the provision 
of costly effort, standard economic theory suggests that monetary incentives could compensate for the effort undertaken, leading to a positive relationship between monetary incentives and the amount of effort expended. On the empirical side, decades of experimental research in psychology and economics has revealed that the relationship between monetary incentives and effort provision may not be as straightforward as predicted by standard economic theory, with some papers showing a positive relationship (Jenkins et al., 1998; DellaVigna and Pope, forthcoming), some showing no relationship (Araujo et al., 2016), and some showing a nonmonotonic relationship (Gneezy and Rustichini, 2000; Pokorny, 2008; Ariely et al., 2009). ${ }^{4}$

The study of the role of monetary incentives is complicated by the fact that there may be non-monetary incentives that influence behavior. This implies that in real-effort experiments, it may be difficult to detect the impact of monetary incentives if it is likely to be overshadowed by the presence of non-monetary incentives. Our aim in this paper, therefore, is to study the impact of monetary and non-monetary incentives by disentangling them. In the real world, monetary as well as non-monetary incentives contribute to effort in important ways. However, the laboratory gives us a chance to analyze the relationship between monetary incentives and effort by mitigating the impact of non-monetary incentives. We show a positive relationship exists between monetary incentives and effort provision, as predicted by standard economic theory.

In the literature on incentive effects, our paper is also related to the group of papers which study the interactions between different type of incentives (see e.g., Deci, Koestner, and Ryan, 1999; Gneezy, Meier, and Rey-Biel, 2011; Bowles and Polanía-Reyes, 2012; Kamenica, 2012). This literature distinguishes between extrinsic and intrinsic motivations and largely focuses on

\footnotetext{
${ }^{4}$ See Camerer and Hogarth (1999) for a survey. Takahashi, Shen, and Ogawa (2016) show that the nature of the task may influence how subjects respond to monetary incentives.
} 
the crowding out of intrinsic motivations by extrinsic rewards. In contrast, focusing on realeffort tasks, we distinguish between monetary and non-monetary incentives. Monetary incentives appeal to an individual's extrinsic motivation, while non-monetary incentives can appeal to an individual's intrinsic (e.g., the inherent desire to win) or extrinsic (e.g., concerns about how one is perceived by others) motivation. Although both monetary and non-monetary incentives co-exist in our Experiment 1, examining crowding-out effects is not the focus of our study. ${ }^{5}$

Our second contribution is to the literature on contests. Unlike most of the studies which analyze monetary incentives using piece-rate schemes, we consider the role of monetary incentives in contests. Contests are used in many economic, political, and social environments. Hence, understanding optimal contest design (i.e., how effort depends on monetary versus nonmonetary incentives in contests) has significant implications for social welfare. As a result, contest behavior has been studied extensively in the laboratory (see Dechenaux, Kovenock, and Sheremeta, 2015 for a survey). However, most of these studies involve a stated-effort design. An important question is whether the results obtained using stated-effort designs continue to hold with real-effort tasks. Our paper provides guidance on how real-effort tasks can be used in contests to study the relationship between incentives and effort. More specifically, we show in Experiment 1 that the positive relationship reported in studies with a stated-effort design does not necessarily hold with a real-effort task. As we show in Experiments 2 and 3, the specific roles that monetary and non-monetary incentives play in contests need to be considered more carefully.

\footnotetext{
${ }^{5}$ The intrinsic vs. extrinsic motivation literature is largely concerned with crowding out of intrinsic motivations in domains such as prosocial activities, lifestyle habits, and education.
} 
Finally, our paper makes a methodological contribution by analyzing the impact of offering different type of outside options in real-effort tasks and comparing their effectiveness in mitigating non-monetary incentives. Several studies have considered outside options as additional features to the design of the tasks. For example, subjects have been provided with the option to leave the laboratory early (e.g., Dickinson, 1999; Rosaz, Slonim, and Villeval, 2016), browse newspapers or magazines (e.g., Charness, Masclet, and Villeval, 2014; ReyBiel, Sheremeta, and Uler, 2017), surf the Internet (e.g., Kessler and Norton, 2016), watch preselected popular YouTube videos (e.g., Hayashi, Nakamura, and Gamage, 2013), press a paid timeout button (e.g., Mohnen, Pokorny, and Sliwka, 2008; Blumkin, Ruffle, and Ganun, 2012), or participate in an alternative activity (e.g., van Dijk, Sonnemans, and van Winden, 2001). ${ }^{6}$ However, a direct comparison of treatments with and without outside options in order to detect the impact of outside options is not the goal of these papers.

Two papers that are more closely related in this regard are Corgnet, Hernán-González, and Schniter (2015) and Eckartz (2014). Corgnet et al. (2015) study the impact of on-the-job leisure on work performance under individual versus team-production incentive schemes. They show that, on average, the availability of the Internet as an outside option has a significant and negative impact on effort under team pay but not under individual pay. Eckartz (2014) studies the impact of different compensation schemes (flat wage, tournament and piece rate) on effort provision. She finds that the availability of a paid pause button as an outside option decreases effort provision under the flat wage scheme, but it has no impact on effort provision under tournament or piece-rate incentives. Although the research objectives of these two papers are different from ours and they consider only one type of outside option, they provide

\footnotetext{
${ }^{6}$ See Kurzban et al. (2013) for a related discussion in the psychology literature about the link between outside options and opportunity cost of effort.
} 
complementary findings in that they also show the introduction of outside options can reduce effort provision. ${ }^{7}$

\section{Experiment 1}

\subsection{Design and Treatments}

Our first experiment aims to investigate whether individuals respond to changes in monetary incentives by altering their effort levels. Subjects participate in a contest to determine how two prizes (Prize 1 and Prize 2) will be allocated between themselves and their matched partner. Each subject $i$ chooses an effort level, $e_{i}$. Subjects make their effort choice by performing a real-effort encryption task (Erkal et al., 2011) for 10 minutes. In this task, each subject is given an encryption table that assigns a number to each letter of the alphabet, and is asked to encrypt a pre-determined sequence of letter combinations by substituting them with numbers using the encryption table. Each combination in the sequence consists of five randomly generated letters, and all the subjects are given the same combinations of letters in the same sequence. Figure 1 shows the screenshot of the task for this treatment.

At the end of 10 minutes, the number of letter combinations that a subject successfully encrypts is defined as his/her effort choice, $e_{i}$. The probability of winning Prize $1, p_{i}\left(e_{i}, e_{j}\right)$, is given by

$$
p_{i}\left(e_{i}, e_{j}\right)=\frac{e_{i}}{e_{i}+e_{j}}
$$

\footnotetext{
${ }^{7}$ See also Gächter, Huang, and Sefton (2016), who introduce a novel real-effort task with an induced cost of effort and show that subjects respond to monetary incentives. Outside of the labor market, Lei, Noussair, and Plott (2001) suggest that the occurrence of bubbles in asset markets in the laboratory may be partly due to the lack of alternative activities that subjects can participate in apart from trading in the asset market.
} 
where $e_{j}$ is the effort level chosen by their matched partner. The subject who does not receive Prize 1 receives Prize 2. If both subjects choose an effort level of zero, then the prizes are allocated randomly.

We vary the monetary incentives by adjusting the value of Prize 1 across three different treatments. Panel (a) of Table 1 provides a summary of the treatments for this experiment. In the Baseline (B) treatment, both Prize 1 and Prize 2 are valued at 150 Experimental Currency Units (ECU). In this treatment, there are no monetary incentives for doing the task since both prizes are equal to each other, and each subject is guaranteed to receive one of the two prizes. In the Baseline - Low (BL) treatment, the value of Prize 1 is increased to 250 ECU, while the value of Prize 2 remains at 150 ECU. In the Baseline - High (BH) treatment, the value of Prize 1 is further increased to 600 ECU. Hence, treatments BL and BH represent situations where there are low and high monetary incentives for doing the task, respectively.

We consider two key variables of interest. First, we are interested in the participation rate, which is the proportion of subjects who exert positive effort. In our analysis, Participation is a dummy variable that takes the value of 1 if a subject exerts positive effort. Second, we are interested in the level of effort per minute, which is defined for those subjects who choose to exert a positive effort level as the average number of letter combinations encrypted per minute. Taken together, these two variables are analogous to the extensive and intensive margins of labor supply commonly used in the labor literature.

\subsection{Hypotheses}

In the absence of any monetary incentives in treatment B, non-monetary incentives (discussed in more detail in Section 4.1) are the key determinants of effort. If the non-monetary incentives are sufficiently strong and higher than the cost of effort, then subjects may choose to exert 
effort even though both Prize 1 and Prize 2 are equal. In fact, evidence from the experimental literature suggests that subjects tend to exert high amounts of effort in real-effort tasks even though there are no additional monetary incentives to be gained from doing so (see, e.g., Kuhnen and Tymula, 2012; Charness et al., 2014; Masclet, Peterle, and Larribeau, 2015). ${ }^{8}$ In line with these previous studies, we conjecture that a significant proportion of subjects will exert positive effort in treatment B.

Hypothesis 1: In the absence of monetary incentives in treatment $B$, subjects will be motivated by non-monetary incentives in their effort choice. Hence, in treatment $B$, both the participation rate and average effort per minute will be greater than zero.

When the value of Prize 1 is increased relative to Prize 2 in treatments $\mathrm{BL}$ and $\mathrm{BH}$, monetary incentives will also be driving behavior. This is because subjects can now receive a monetary gain by exerting effort to increase their probability of receiving the higher prize. Consequently, we expect effort provision to be the lowest in treatment B and to increase as the value of Prize 1 increases.

Hypothesis 2: The presence of monetary incentives in addition to non-monetary incentives in treatments $B L$ and $B H$ will lead to higher participation and effort per minute in these treatments as compared to treatment B. Moreover, increasing monetary incentives will result in an increase in both the participation rate and effort per minute in treatment BH as compared to treatment $B L$.

\footnotetext{
${ }^{8}$ Similar results are reported in the psychology literature (see, e.g., Huxtable, White, and McCartor, 1946; Orne, 1962) which show that subjects exert effort for many hours (even days) with insignificant amounts of monetary incentives.
} 


\subsection{Procedures}

Our experiments were conducted between August and November 2015 in the Experimental Economics Laboratory at the University of Melbourne ( $\left.\mathrm{E}^{2} \mathrm{MU}\right)$ and programmed using z-Tree (Fischbacher, 2007). Subjects were recruited using ORSEE (Greiner, 2015) and consisted mostly of students from the University of Melbourne. Our experiment follows a betweensubject treatment design where subjects were randomly assigned into one of the three treatments. We ran two sessions for each treatment, with 24-28 subjects in each session. Each session lasted between 60 and 90 minutes, including time for reading the instructions and the administration of payments. We collected 156 independent observations in total for Experiment 1.

Upon entering the laboratory, subjects first participated individually in a one-shot risk task (Gneezy and Potters, 1997). Each subject was given an endowment of 50 ECU and had to decide how much of this endowment to allocate between a risky investment and a risk-free investment. With equal probabilities, the risky investment either returned three times the amount invested or nothing.

After completing the risk task, subjects received the instructions for the contest task. ${ }^{9}$ Subjects were randomly divided into pairs, and they did not know the identity of their matched partners. Instructions were summarized verbally by the experimenter, and subjects participated in a practice real-effort task for three minutes to allow them to familiarize themselves with the interface of the task.

At the end of the experiment, subjects were asked to answer a questionnaire which included basic demographic questions as well as questions about their decisions during the

\footnotetext{
${ }^{9}$ Instructions are available in Online Appendix A.
} 
experiment. Once they completed the questionnaire, subjects were paid their earnings privately. Subjects were randomly paid for their decisions in either the risk task or the contest task, and this was determined at the session level. ${ }^{10}$ Subjects did not learn the outcomes of the tasks until the end of the experiment. Earnings were converted to Australian dollars (AUD) at the rate 10 ECU = 1 AUD and included a \$10 show-up fee. Subjects earned between $\$ 10$ and $\$ 70$, with the mean earnings being $\$ 22.59$.

\subsection{Results}

Figure 2 presents histograms of the distribution of effort in treatments B, BL, and BH. Overall, the histograms show that: (i) a large number of subjects choose to exert positive effort in all three treatments; and (ii) the distribution of effort is almost identical across the three treatments. A Kruskal-Wallis equality-of-populations rank test fails to reject the null hypothesis that the distribution of effort in treatments B, BL, and BH are equal to one another ( $\mathrm{p}$-value $=0.241$ ). Pairwise Kolmogorov-Smirnov tests for the equality of distribution functions also fail to reject the null hypotheses that the distributions of effort between any pair of treatments are equal to each other (B vs. BL: p-value = 0.296; B vs. BH: p-value = 0.685; BL vs. BH: p-value = 0.831).

Panel (a) of Table 2 presents the participation rate and average effort per minute conditional on participating. Overall, almost all of the subjects (96\%) exert positive effort in the absence of monetary incentives in treatment B. Conditional on participation, these subjects also exert a non-trivial amount of effort, with the average effort per minute being 4.22. Hence, we find support for Hypothesis 1 in that subjects are motivated by non-monetary incentives in their effort choice and choose to exert high effort even in the absence of monetary incentives.

\footnotetext{
${ }^{10}$ This payment mechanism is commonly used in the experimental literature. Bardsley et al. (2010) show that it is incentive compatible under the assumption of expected utility maximization. They also discuss the validity of using this mechanism when agents are not expected utility maximizers.
} 
One may argue that this result is sensitive to the length and type of the specific task used in our experiment. Fatigue and boredom may play more important roles if the task is longer or different. Hence, in such environments, the impact of non-monetary incentives may be weaker. To test this, we ran two variants of treatment B. In the 20-Minute (20-Min) treatment, subjects performed the encryption task for 20 minutes instead of 10 minutes $(\mathrm{N}=56)$. In the Slider $(\mathrm{S})$ treatment, the subjects participated in a slider task (Gill and Prowse, 2012) instead of the encryption task $(\mathrm{N}=54)$. We find no statistically significant differences in behavior between treatment B and these two treatments. ${ }^{11}$

Panel (a) of Table 2 also reveals that when monetary incentives are present, $100 \%$ of subjects exert positive effort in both of the treatments (BL and $\mathrm{BH}$ ). Pairwise Fisher's exact tests fail to reject the null hypotheses that the participation rates are equal between the treatments with monetary incentives and the baseline treatment $(\mathrm{B}$ vs. $\mathrm{BL}$ : $\mathrm{p}$-value $=0.496$; $\mathrm{B}$ vs. $\mathrm{BH}$ : p-value $=0.495$ ). Conditional on participating, the average effort per minute is 4.49 in treatment $\mathrm{BL}$ and 4.33 in treatment $\mathrm{BH}$. Pairwise Wilcoxon rank-sum tests fail to reject the null hypotheses that the effort per minute between any pair of treatments are equal to each other (B vs. BL: p-value $=0.172$; $\mathrm{B}$ vs. $\mathrm{BH}$ : p-value $=0.421 ; \mathrm{BL}$ vs. $\mathrm{BH}$ : $\mathrm{p}$-value $=0.601$ ).

Table 3 presents the coefficient estimates from OLS regressions of participation (column 1) and effort per minute (column 2) on treatment variables and subjects' characteristics, which include the percentage of the endowment invested in the risk task, age, gender, study level at University, whether the subject is pursuing a major in economics, whether the subject is Australian, and previous experience with economic experiments. The table also presents the

\footnotetext{
${ }^{11}$ The details of these treatments can be found in Online Appendix B. It is possible that considering even longer tasks may create a bigger opportunity for monetary incentives to affect behavior. Further exploration of this issue is beyond the scope of the current paper. Our design choice is guided by the literature where most experiments do not include such long tasks.
} 
test of equality between the estimated coefficients for treatments $\mathrm{BL}$ and $\mathrm{BH}$. Treatment $\mathrm{B}$ is the reference treatment for both regressions.

The regression estimates are consistent with the conclusions from the non-parametric tests, with the exception of the estimated coefficient on treatment BL in column (2). The estimated coefficient reveals that, conditional on participating, effort per minute is 0.329 higher on average when low monetary incentives are present as compared to when no monetary incentives are present. This effect is statistically significant at the $5 \%$ level (p-value $=0.015$ ). To investigate this issue further, column (3) presents the results for median effort using a quantile regression. Consistent with the conclusions from our non-parametric tests, the coefficient estimates indicate that introducing monetary incentives (treatments B vs. BL) and increasing monetary incentives (treatments $\mathrm{BL}$ vs. BH) have no significant impact on the median effort. ${ }^{12}$

In summary, consistent with the results from the literature, we fail to find systematic support for Hypothesis 2. The regression estimates using average effort suggest that introducing monetary incentives may have an impact on effort per minute. However, this effect is not observed with the non-parametric analysis or when we consider median effort. Increasing monetary incentives from treatment BL to treatment BH does not have a statistically significant impact on the participation rate and effort per minute either.

The results from Experiment 1 suggest that non-monetary incentives are present and lead to high effort even in the absence of monetary incentives. This may make it difficult to capture

\footnotetext{
${ }^{12}$ Given that participation is similar across the three treatments in Experiment 1, total performance is another measure that can be used to analyze the data. The results for unconditional effort per minute (total effort divided by the total time spent on the task) are qualitatively similar to those for conditional effort per minute, with the exception that the difference between treatments B and BL is statistically significant. This result seems to be driven by the two subjects in treatment $B$ who exert zero effort and disappears when we consider quantile (median) regressions. The results for unconditional and conditional effort are similar in Experiments 2 and 3. Details are available from the authors upon request.
} 
whether subjects respond to monetary incentives in real-effort tasks within the laboratory. This is problematic if our goal is to study the responsiveness of effort to monetary incentives. Hence, we next explore whether we can detect the impact for monetary incentives if we reduce the impact of non-monetary incentives.

\section{Experiment 2}

\subsection{Framework}

Our design in Experiment 2 is motivated by the following simple framework, where subjects participating in real-effort tasks are assumed to make their effort choices by comparing the marginal cost and marginal benefit of exerting one more unit of effort. Formally, let $e_{i}$ denote the effort chosen by subject $i$. We assume that the marginal cost of effort is determined by the opportunity cost of time and is convex in effort $\left(c e_{i}^{2}\right)$. For example, the opportunity cost of time in Experiment 1 is determined by sitting idle and daydreaming. ${ }^{13}$

On the benefit side, let $V_{1}$ and $V_{2}$ represent the value of Prize 1 and Prize 2, respectively. Hence, $V_{2}+\frac{e_{i}}{e_{i}+e_{j}}\left(V_{1}-V_{2}\right)$ is the monetary payoff subjects expect to receive in a two-player contest. In addition to monetary incentives, subjects’ behavior may also be influenced by: (i) curiosity for the task or enjoyment of the task; (ii) the utility derived from doing what is expected of them or being useful/productive (experimenter demand effect); ${ }^{14}$ and (iii) the utility derived from being the winner in a competitive environment. ${ }^{15}$ Assuming concavity, we

\footnotetext{
${ }^{13}$ Subjects were not allowed to have access to their phones or books during the experiment.

${ }^{14}$ Experimenter demand effect refers to the expectations that subjects form about their effort/performance based on the cues that they receive from the environment created by the experimenter (e.g., from the experimenter's instructions). Note that it is also possible for their expectations to be shaped by other factors, such as the goals they may set for themselves.

${ }^{15}$ These non-monetary incentives have been found to influence subjects' behavior in other environments also (see, e.g., Carpenter, Liati, and Vickery, 2010; Sheremeta, 2010; Zizzo, 2010). In a related paper, DellaVigna and Pope (forthcoming) consider other types of non-monetary motivators of behavior, namely social preferences, present bias, reference dependence, social comparison, and task significance.
} 
let $b_{1} \log \left(e_{i}\right)$ and $b_{2} \log \left(e_{i}\right)$ stand for (i) and (ii), respectively. Since we do not have public announcement of winners in our design, (iii) corresponds to the utility that subjects may derive from privately receiving the title of "recipient of Prize 1" at the end of the experiment. Given that a subject receives this benefit only if s/he wins the contest, $b_{3} \frac{e_{i}}{e_{i}+e_{j}}$ stands for (iii).

Putting these together, individual $i$ solves

$$
\max _{e_{i}} V_{2}+\frac{e_{i}}{e_{i}+e_{j}}\left(V_{1}-V_{2}\right)+b_{1} \log \left(e_{i}\right)+b_{2} \log \left(e_{i}\right)+b_{3} \frac{e_{i}}{e_{i}+e_{j}}-c e_{i}^{2}
$$

Since we are interested in studying non-monetary incentives, we remove the monetary incentives in Experiment 2 by setting $V_{1}=V_{2}=150$ ECU. ${ }^{16}$ Then, the following first-order condition (FOC) defines the optimal effort of subject $i$ :

$$
\frac{b_{1}+b_{2}}{e_{i}}+\frac{e_{j}}{\left(e_{i}+e_{j}\right)^{2}} b_{3}=2 c e_{i} \text {. }
$$

From equation (2), it is clear that effort can be reduced either by decreasing $b_{1}, b_{2}$, and $b_{3}$, or by increasing $c$.

\subsection{Treatments and Hypotheses}

Panel (b) of Table 1 presents a summary of the three treatments designed for this purpose. All three treatments follow the same setup as in Experiment 1 with the modifications we explain below. Treatment B from Experiment 1 serves as the baseline treatment for comparison in this experiment.

In Experiment 1, the opportunity cost of effort, $c$, depends on the utility derived from sitting idle. The first two treatments in Experiment 2 aim to increase $c$ in equation (2).

\footnotetext{
${ }^{16}$ The formulation we present assumes that monetary and non-monetary incentives are additively separable as in Frey and Oberholzer-Gee (1997) and DellaVigna and Pope (forthcoming). See Bowles and Polanía-Reyes (2012) for an alternative, non-separable formulation.
} 
Specifically, in the Early Departure (ED) treatment, subjects are permitted to leave the experiment at any time during the task. If they wish to leave the experiment early, they can click a button on the screen to stop the task. In this case, they still receive 150 ECU for this task since both prizes are of the same monetary value. Once they stop the task, these subjects are invited to complete the questionnaire, and are then paid their earnings in private before leaving the laboratory.

In the Pause $(\mathrm{P})$ treatment, subjects are permitted to take timeout at any time during the real-effort task and as many times as they wish. To take timeout, they have to click a button on the screen to pause the task temporarily. Subjects receive 5 ECU per minute they spend in timeout which is paid on a pro rata basis. While taking timeout, subjects can click another button on the screen to return to the task at any time.

In summary, in treatment ED, the opportunity cost of effort is given by the value of the time spent doing something outside of the laboratory (e.g., enjoying the company of one's friends). In treatment $\mathrm{P}$, the opportunity cost of effort has an explicit monetary value, 5 ECU per minute. ${ }^{17}$ The values of these outside options are likely to be higher than the value of sitting idle. Our hypothesis regarding these two treatments is the following.

Hypothesis 3: Allowing subjects to leave the experiment early and/or introducing an incentivized timeout button will increase the opportunity cost of effort. Hence, relative to treatment $B$, both the participation rate and average effort per minute will be lower in treatments ED and $P$.

\footnotetext{
${ }^{17}$ Eckartz (2014) and Mohnen et al. (2008) also use an incentivized timeout button as an outside option in their design, while Dickinson (1999) uses early departure to study on- and off-the-job leisure. We considered treatments with other outside options as well, such as newspapers/magazines or the Internet. However, results from our pilot experiments suggest that, within the timeframe provided for the real-effort task (10 minutes), these outside options do not significantly influence subjects' behavior in the laboratory. Hence, we decided not to proceed with these treatments.
} 
The third treatment in Experiment 2 is designed to increase $c$ (the opportunity cost of effort), reduce $b_{1}$ (task enjoyment), and reduce $b_{2}$ (experimenter demand effect) at the same time. To this end, in the Activity 1/2 (A1A2) treatment, subjects are provided with two activities simultaneously on the same screen. Figure 3 shows the screenshot of the task for this treatment. Activity 1 is located on the top half of the screen while Activity 2 is located on the bottom half. In both activities, subjects participate in the encryption task, but with different sets of letter combinations and encryption tables. The payment scheme for Activity 1 is exactly the same as in treatment B, where the number of letter combinations encrypted by a pair of subjects determines how Prize 1 and Prize 2, which are equal to each other, will be allocated between them. In Activity 2, subjects participate in the task individually and are paid a piece rate of 1.25 ECU for each letter combination encrypted. ${ }^{18}$ Subjects can choose to do only one, both, or none of the activities, and they can switch between the two activities at any time during the task and as many times as they want. Their payment from this part of the experiment is the sum of the payments received from Activity 1 and Activity $2{ }^{19}$

In treatment A1A2, conditional on choosing to exert effort on the task, subjects decide how to allocate their effort between the two activities. We are mainly interested in the effort exerted in Activity 1 since Activity 2 is considered to be the outside option. More specifically, the decision to put in effort in Activity 2 is similar to taking a timeout (as in treatment $\mathrm{P}$ ), except that the subject now has to work to receive the timeout payment. As a result, the piece

\footnotetext{
${ }^{18}$ We calibrate the piece rate such that, if a subject spends all his/her time on Activity 2, then s/he will receive 50 ECU from Activity 2 on average, which is the same as the total timeout payment available in treatment P. This calibration is done using the average number of letter combinations encrypted by subjects within 10 minutes in our pilot experiments.

${ }^{19}$ Similarly, van Dijk et al. (2001) consider a design with two activities to investigate the impact of different incentive schemes. Johnson and Salmon (2016) also introduce an alternative activity (a counting task) as an outside option to their main real-effort task (a number adding task). Since the two activities are different, subjects may continue to be motivated by task enjoyment or curiosity in their effort decisions.
} 
rate earned in Activity 2 is the opportunity cost of exerting effort in Activity 1. Moreover, since Activity 2 is based on the same task as Activity 1, we expect that task enjoyment and experimenter demand effect will no longer be the drivers of effort in Activity 1. This is because subjects can derive the same utility from these two factors in both Activity 1 and Activity 2. Hence, we would expect only those subjects who are sufficiently competitive to exert effort in Activity 1.

Formally, subject $i$ in treatment A1A2 solves

$$
\max _{e_{1, i}, e_{2, i}} V_{2}+\rho e_{2, i}+\left(b_{1}+b_{2}\right) \log \left(e_{1, i}+e_{2, i}\right)+b_{3} \frac{e_{1, i}}{e_{1, i}+e_{1, j}}-c\left(e_{1, i}+e_{2, i}\right)^{2}
$$

where $e_{1, i}$ and $e_{2, i}$ are the effort exerted by individual $i$ in Activity 1 and Activity 2, respectively, and $\rho$ is the piece rate paid per unit of effort exerted in Activity 2. The FOCs with respect to $e_{1, i}$ and $e_{2, i}$ are given by

$$
\frac{\left(b_{1}+b_{2}\right)}{e_{1, i}+e_{2, i}}+b_{3} \frac{e_{1, j}}{\left(e_{1, i}+e_{1, j}\right)^{2}}=2 c\left(e_{1, i}+e_{2, i}\right)
$$

and

$$
\frac{\left(b_{1}+b_{2}\right)}{e_{1, i}+e_{2, i}}+\rho=2 c\left(e_{1, i}+e_{2, i}\right),
$$

respectively. These two equations, when combined, give us

$$
b_{3} \frac{e_{1, j}}{\left(e_{1, i}+e_{1, j}\right)^{2}}=\rho .
$$

Equation (4) implies that subject $i$ 's effort allocation will be such that on the margin, the benefit derived from being the recipient of Prize 1 in Activity 1 is equal to the piece rate received in Activity 2. Hence, $b_{1}$ and $b_{2}$ no longer play a role in the allocation of effort between Activity 1 and Activity 2. However, if $b_{3}$ is sufficiently high, then we would expect subjects to exert a positive level of effort in Activity 1. Nevertheless, the average participation and effort 
levels in Activity 1 should be lower than those in treatment B. This leads us to the following hypothesis for treatment A1A2.

\section{Hypothesis 4:}

(i) Providing an alternative activity that pays a piece rate will increase the opportunity cost of effort and remove the impact of task enjoyment and experimenter demand effect on effort provision in Activity 1 of treatment A1A2. Hence, relative to treatment B, both the participation rate and average effort per minute will be lower in Activity 1 of treatment A1A2.

(ii) Since subjects may still be motivated by a desire to be the recipient of Prize 1 in the contest (competitiveness), both the participation rate and average effort per minute in Activity 1 of treatment A1A2 will be greater than zero.

The treatments for Experiment 2 were also conducted in the $\mathrm{E}^{2} \mathrm{MU}$ lab, and they followed the same procedures as in Experiment 1. We ran two sessions each for treatments ED, P, and A1A2, and collected a total of 162 independent observations in these treatments. Subjects earned between $\$ 10$ and $\$ 32.90$, with the mean earnings being $\$ 22.56$.

\subsection{Results}

Figure 4 shows the histograms of the subjects' effort choices by treatment. While the majority of subjects exert high effort in the baseline treatment $\mathrm{B}$, this is no longer the case in treatments ED, P, and A1A2. Pairwise Kolmogorov-Smirnov tests reject the null hypotheses that the distribution of effort in treatments ED, $\mathrm{P}$, and $\mathrm{A} 1 \mathrm{~A} 2$, are equal to that in treatment $\mathrm{B}$ (B vs. ED: -value $=0.000 ;$ B vs. P: p-value $=0.000 ;$ B vs. A1A2: -value $=0.000$ ). 
Panel (b) of Table 2 presents summary statistics at the treatment level. The participation rates in treatments ED (82\%), P (54\%), and A1A2 (38\%) are lower than that in the baseline treatment B (96\%). Pairwise Fisher's exact tests reject the null hypotheses that the participation rates in these treatments are equal to that in treatment $\mathrm{B}$ (B vs. ED: $\mathrm{p}$-value $=0.025$; $\mathrm{B}$ vs. $\mathrm{P}$ : $\mathrm{p}$-value $=0.000 ; \mathrm{B}$ vs. A1A2: $\mathrm{p}$-value $=0.000)$. Conditional on participation, the average effort per minute is 3.27 in treatment ED, 0.94 in treatment $\mathrm{P}$, and 0.54 in treatment A1A2, all of which are lower than that in treatment B (4.22). Pairwise Wilcoxon rank-sum tests reject the null hypotheses that the effort per minute in these treatments are equal to that in treatment $\mathrm{B}$ (B vs. ED: -value $=0.000$; B vs. P: p-value $=0.000$; vs. A1A2: -value $=0.000$ ). Overall, the results suggest that these treatments are effective in reducing effort on both the extensive and intensive margins.

Table 4 presents the results of OLS and quantile (median) regressions of participation (column 1) and effort per minute (columns 2 and 3). For all regressions, Treatment B is the reference treatment. The regression estimates for treatments ED, P and A1A2 are consistent with the conclusions from the non-parametric tests. Both the participation rate and average effort per minute in these treatments are significantly lower than those in treatment B. Hence, we find support for Hypotheses 3 and 4(i).

Panel (b) of Table 2 also reveals that a non-trivial proportion of the subjects (38\%) exert positive effort in Activity 1 of treatment A1A2. Conditional on participation, the average effort per minute is 0.54 , suggesting that subjects exert a small amount of effort so that they have a positive probability of receiving Prize 1. Hence, we conclude that, in support of Hypothesis 4(ii), despite the high opportunity cost of exerting effort in Activity 1 (given by the piece rate 
in Activity 2) and the lack of monetary incentives, some subjects still choose to exert effort in this activity. ${ }^{20}$

We next explore which of the treatments ED, P, and A1A2 is more effective in mitigating the impact of non-monetary incentives. Pairwise Kolmogorov-Smirnov tests reject the null hypotheses that the distribution of effort in treatments ED, P, and A1A2 are equal to one another $(\mathrm{ED}$ vs. $\mathrm{P}$ : $\mathrm{p}$-value $=0.000 ; \mathrm{ED}$ vs. $\mathrm{A} 1 \mathrm{~A} 2$ : $\mathrm{p}$-value $=0.000 ; \mathrm{P}$ vs. $\mathrm{A} 1 \mathrm{~A} 2: \mathrm{p}$-value $=$ 0.060). From panel (b) of Table 2, we observe that among these three treatments, both the participation rate and average effort per minute are the highest in treatment ED and the lowest in treatment A1A2. Pairwise Fisher's exact tests and Wilcoxon rank-sum tests reveal that both the participation rate and effort per minute in treatment ED are significantly higher than those in treatments P and A1A2 (Pairwise Fisher's exact tests: ED vs. P: p-value $=0.002$, ED vs. A1A2: -value $=0.000$; Pairwise Wilcoxon rank-sum tests: ED vs. P: p-value $=0.000$, ED vs. A1A2: $\mathrm{p}$-value $=0.000$ ). Hence, of these three treatments, treatment ED is the least effective method for mitigating the impact of non-monetary incentives.

A comparison between treatments A1A2 and P reveals that the participation rates between these two treatments are not significantly different from each other (Fisher's exact test: P vs. A1A2: $p$-value $=0.125)$. However, conditional on participating, the effort per minute in Activity 1 of treatment A1A2 is statistically significantly lower than that in treatment $\mathrm{P}$ (Wilcoxon rank-sum test: $\mathrm{p}$-value $=0.026$ ). Hence, while providing subjects with an alternative activity that pays a piece rate is no more effective in reducing participation than introducing an

\footnotetext{
${ }^{20}$ Competitiveness can affect behavior in a contest even in the absence of a real-effort task. In an additional treatment that we ran with stated effort (treatment EC, $N=56$ ), where we had the same parameters for Prize 1 and Prize 2 as in treatment B, we find that the behavior of the subjects is largely similar to that in Activity 1 of treatment A1A2. This finding is consistent with Sheremeta (2010). The details can be found in Online Appendix B.
} 
incentivized timeout button, it is the most effective method in reducing subjects' effort level conditional on participating.

\section{Experiment 3}

\subsection{Treatments and Hypotheses}

Experiment 3, similar to Experiment 1, aims to detect responses to changes in monetary incentives. However, we now mitigate the impact of non-monetary incentives by using the insights from Experiment 2. Since we find treatment A1A2 to be the most effective, we choose to implement this treatment in Experiment 3 and vary monetary incentives.

Panel (c) of Table 1 provides a summary of the treatments in Experiment 3. In treatments A1A2-L and A1A2-H, we vary the value of Prize 1. In parallel with treatments BL and BH, Prize 1 is 250 ECU in treatment A1A2-L and 600 ECU in treatment A1A2-H. Hence, equation

(4) becomes

$$
\frac{e_{1, j}}{\left(e_{1, i}+e_{1, j}\right)^{2}}\left(V_{1}-V_{2}\right)+b_{3} \frac{e_{1, j}}{\left(e_{1, i}+e_{1, j}\right)^{2}}=\rho
$$

Since the impact of non-monetary incentives is reduced in these treatments, we expect monetary incentives to have a significant impact on participation and effort per minute in Activity $1 .^{21}$

\footnotetext{
${ }^{21}$ Note that, despite the introduction of monetary incentives (which means subjects can now earn more by investing in Activity 1), subjects may still choose Activity 2 (which pays a piece rate) over Activity 1 if they have low confidence in their ability or if they are concerned about creating unequal payments (social preferences). Hence, any impact we find can be considered as a lower bound on incentive effects since the impact of monetary incentives may be higher in an environment without these considerations. We thank a reviewer for pointing this out to us.
} 
Hypothesis 5: Both participation and effort per minute will increase monotonically as the value of Prize 1 increases from 150 ECU (treatment A1A2) to 250 ECU (treatment A1A2-L) and 600 ECU (treatment A1A2-H).

Treatments A1A2-L and A1A2-H were also conducted in the $\mathrm{E}^{2} \mathrm{MU}$ lab, and they followed the same procedures as in Experiments 1 and 2. As before, we ran two sessions for each treatment and collected a total of 108 independent observations in these two treatments. Subjects earned between $\$ 10$ and $\$ 75.40$, with the mean earnings being $\$ 28.81$.

\subsection{Results}

Figure 5 presents histograms of the distribution of effort in treatments A1A2, A1A2-L, and A1A2-H. A comparison of Figures 2 and 5 reveals that the distribution of effort in these three treatments are in stark contrast to the distribution of effort in treatments $\mathrm{B}, \mathrm{BL}$, and $\mathrm{BH}$ in Experiment 1. In the absence of monetary incentives (A1A2), the majority of the subjects exert zero or close to zero effort. When low incentives are present (A1A2-L), almost all the subjects appear to exert positive effort, although the distribution is still slightly skewed to the right. When high incentives are present (A1A2-H), the distribution of effort is now skewed to the left such that more than half of the subjects are exerting effort levels of 30 and above. A KruskalWallis equality-of-populations rank test rejects the null hypothesis that the distribution of effort in treatments $\mathrm{A} 1 \mathrm{~A} 2, \mathrm{~A} 1 \mathrm{~A} 2-\mathrm{L}$, and $\mathrm{A} 1 \mathrm{~A} 2-\mathrm{H}$ are equal to one another ( $\mathrm{p}$-value $=0.000$ ). Pairwise Kolmogorov-Smirnov tests also reject the null hypotheses that the distributions of effort between any pair of treatments are equal to each other (A1A2 vs. A1A2-L: p-value = 0.000; A1A2 vs. A1A2-H: p-value = 0.000; A1A2-L vs. A1A2-H: $\mathrm{p}$-value $=0.057$ ). 
Panel (c) of Table 2 presents the participation rate and average effort per minute conditional on participation in each treatment. In the absence of monetary incentives (treatment A1A2), the participation rate is $38 \%$. The participation rate jumps to $98 \%$ when low incentives are present (treatment A1A2-L) and 96\% when high incentives are present (treatment A1A2$\mathrm{H})$. Hence, the participation rate increases to almost $100 \%$ in treatment A1A2-L, leaving no room for further improvement in treatment A1A2-H (Pairwise Fisher's exact test, A1A2 vs. A1A2-L: p-value $=0.000 ;$ A1A2 vs. A1A2-H: p-value $=0.000 ;$ A1A2-L vs. A1A2-H: p-value $=0.608)$.

Conditional on participating, the average effort per minute is 0.54 in treatment A1A2. In the presence of monetary incentives, the average effort per minute increases to 2.52 in treatment A1A2-L and 3.27 in treatment A1A2-H. Pairwise Wilcoxon rank-sum tests reject the null hypotheses that the effort per minute between any pair of treatments are equal to each other $(\mathrm{A} 1 \mathrm{~A} 2$ vs. A1A2-L: $\mathrm{p}$-value $=0.000 ; \mathrm{A} 1 \mathrm{~A} 2$ vs. A1A2-H: $\mathrm{p}$-value $=0.000 ; \mathrm{A} 1 \mathrm{~A} 2-\mathrm{L}$ vs. A1A2$\mathrm{H}$ : $\mathrm{p}$-value $=0.020)$. Hence, on the intensive margin, we observe a monotonic response in subjects' effort levels to changes in monetary incentives.

Table 5 shows that the results of OLS and quantile (median) regressions of participation (column 1) and effort per minute (columns 2 and 3) are in line with the results from the nonparametric tests. The table presents the test of equality between the estimated coefficients for treatments A1A2-L and A1A2-H. Treatment A1A2 is the reference treatment for all regressions.

In summary, Experiment 3 demonstrates that when non-monetary benefits are reduced and opportunity cost of effort is increased with the introduction of an alternative activity, we are 
able to detect a significant response to changes in monetary incentives. ${ }^{22}$ The introduction of monetary incentives in treatment A1A2-L increases participation to almost $100 \%$ and has a significant positive impact on effort per minute. Increasing monetary incentives from treatment A1A2-L to treatment A1A2-H has a further significant impact on effort per minute. These results stand in contrast to what we obtain in Experiment 1 with the baseline treatments $(\mathrm{B}, \mathrm{BL}$, and $\mathrm{BH}$ ), where we fail to detect a consistent response to changes in monetary incentives.

\section{Conclusion}

In recent years, real-effort tasks have been growing in popularity. In this paper, we design three real-effort experiments spanning eight treatments to examine a fundamental question in economics about whether subjects respond to monetary incentives in their effort choice. Evidence from the laboratory has thus far provided mixed findings on the relationship between monetary incentives and effort provision. We re-visit this issue in Experiment 1 within a twoplayer real-effort contest and find that subjects exert significantly high effort even in the absence of monetary incentives, suggesting that they are motivated by non-monetary incentives. Moreover, we do not find any systematic changes in effort provision when monetary incentives are increased.

Interestingly, we find that monetary incentives have a positive impact on effort provision once the impact of non-monetary incentives is reduced. Experiments 2 and 3 reveal that introducing an alternative activity that pays a piece rate is the most effective way of mitigating

\footnotetext{
${ }^{22}$ Using a piece-rate scheme, DellaVigna and Pope (forthcoming) also find that subjects respond positively to increases in monetary incentives. This is consistent with our result in Experiment 3, but it contrasts the findings of Araujo et al. (2016) (who also use a piece rate) and our Experiment 1. A possible explanation is that their study was done using Amazon Mechanical Turk (MTurk) where subjects readily have outside options (e.g., to browse the Internet or perform other MTurk tasks/experiments), whereas the evidence presented in Araujo et al. (2016) is based on laboratory experiments where the subjects have a much lower opportunity cost of participating in the real-effort task (as in our Experiment 1).
} 
the impact of non-monetary incentives by both increasing the opportunity cost of effort and directly decreasing the non-monetary benefits that are present. By altering both the benefit and cost side of effort provision, this treatment aims to replicate most modern work environments where individuals can choose how to spend their time at work. While paid outside options may not necessarily be available in workplaces, outside options can take other forms, such as chatting with co-workers, browsing the Internet, going for a coffee break etc. Although there may be no explicit monetary incentives associated with these outside options, individuals still derive some positive utility from them.

Workers in real-world workplaces are motivated by a myriad of factors (see, e.g., Besley and Ghatak, 2005; Akerlof and Kranton, 2010). Both monetary as well as non-monetary factors, such as whether an individual likes the job s/he is doing, play a role in effort provision. Nevertheless, when studying effort provision in the laboratory (using a real-effort task), we posit that the existence of non-monetary incentives may diminish the ability of researchers to detect any response to changes in monetary incentives. Hence, researchers may find it useful to study the impact of monetary and non-monetary incentives on effort provision separately. We provide a framework for doing this.

Beyond studying the economic question of the relationship between monetary incentives and effort provision, this paper also provides insights to researchers who are considering the use of real-effort tasks as part of their research strategy. Since subjects are motivated by nonmonetary incentives in their real-effort choices, any impact this may have on outcomes should be taken into account. For instance, if the researcher is interested in using a real-effort task to assign subjects into different groups and/or roles, then s/he will need to be aware of potential selection effects since the sorting of subjects may be based on the subjects' responses to non- 
monetary incentives. A failure to control or account for this selection effect can lead to selection based on unobservable characteristics and consequently, false conclusions.

Consider, for example, a researcher who is interested in studying the impact of income earned on subsequent decisions (such as charitable giving). If non-monetary incentives, such as curiosity about the task, play a more important role in the determination of effort choices than monetary incentives, then the high earners may be those individuals who have a higher level of curiosity than the rest of the population. As a result, their decisions in the later stages of the experiment may be driven by this qualification rather than differences in income levels. If the researcher ignores this fact, then the causal effect may be misidentified. Mitigating the impact of non-monetary incentives in order to isolate the impact of monetary incentives can be useful in such cases. 


\section{References}

Abeler, J., Falk, A., Goette, L., \& Huffman, D. (2011). Reference points and effort provision. American Economic Review, 101(2), 470-492.

Akerlof, G. A., \& Kranton, R. E. (2010). Identity economics: How our identities shape our work, wages, and well-being. Princeton: Princeton University Press.

Araujo, F. A., Carbone, E., Conell-Price, L., Dunietz, M. W., Jaroszewicz, A., Landsman, R., Lamé, D., Vesterlund, L., Wang, S., \& Wilson, A. J. (2016). The slider task: An example of restricted inference on incentive effects. Journal of the Economic Science Association, 2(1), 1-12.

Ariely, D., Gneezy, U., Loewenstein, G., \& Mazar, N. (2009). Large stakes and big mistakes. The Review of Economic Studies, 76, 451-469.

Bardsley, N., Cubitt, R., Loomes, G., Moffatt, P., Starmer, C., \& Sugden, R. (2010). Experimental economics: Rethinking the rules. Woodstock: Princeton University Press.

Berger, J., \& Pope, D. (2011). Can losing lead to winning? Management Science, 57(5), 817827.

Besley, T., \& Ghatak, M. (2005). Competition and incentives with motivated agents. American Economic Review, 95(3), 616-636.

Blumkin, T., Ruffle, B. J., \& Ganun, Y. (2012). Are income and consumption taxes ever really equivalent? Evidence from a real-effort experiment with real goods. European Economic Review, 56(6), 1200-1219.

Bowles, S., \& Polanía-Reyes, S. (2012). Economic incentives and social preferences: Substitutes or complements? Journal of Economic Literature, 50(2), 368-425.

Camerer, C. F., \& Hogarth, R. M. (1999). The effects of financial incentives in experiments: A review and capital-labor-production framework. Journal of Risk and Uncertainty, 19(1/3), 7-42.

Carpenter, J., Liati, A., \& Vickery, B. (2010). They come to play: Supply effects in an economic experiment. Rationality and Society, 22(1), 83-102.

Carpenter, J., Matthews, P. H., \& Schirm, J. (2010). Tournaments and office politics: Evidence from a real effort experiment. American Economic Review, 100(1), 1-18.

Charness, G., \& Kuhn, P. (2011). Lab labor: What can labor economists learn from the lab? In O. Ashenfelter \& D. Card (Eds.), Handbook of Labor Economics (Vol. 4a, pp. 229330). North Holland: Elsevier.

Charness, G., Masclet, D., \& Villeval, M. C. (2014). The dark side of competition for status. Management Science, 60(1), 38-55. 
Corgnet, B., Hernán-González, R., \& Schniter, E. (2015). Why real leisure really matters: Incentive effects on real effort in the laboratory. Experimental Economics, 18(2), 284301.

Dechenaux, E., Kovenock, D., \& Sheremeta, R. M. (2015). A survey of experimental research on contests, all-pay auctions and tournaments. Experimental Economics, 18(4), 609669.

Deci, E. L., Koestner, R., \& Ryan, R. M. (1999). A meta-analytic review of experiments examining the effects of extrinsic rewards on intrinsic motivation. Psychological Bulletin, 125(6), 627-668.

DellaVigna, S., List, J. A., Malmendier, U., \& Rao, G. (2016). Estimating social preferences and gift exchange at work. Working Paper.

DellaVigna, S., \& Pope, D. (forthcoming). What motivates effort? Evidence and expert forecasts. Review of Economic Studies.

Dickinson, D. L. (1999). An experimental examination of labor supply and work intensities. Journal of Labor Economics, 17(4), 638-670.

Eckartz, K. M. (2014). Task enjoyment and opportunity costs in the lab - the effect of financial incentives on performance in real effort tasks. Jena Economic Research Papers, 5.

Eriksson, T., Mao, L., \& Villeval, M. C. (2017). Saving face and group identity. Experimental Economics, 20(3), 622-647.

Erkal, N., Gangadharan, L., \& Nikiforakis, N. (2011). Relative earnings and giving in a realeffort experiment. American Economic Review, 101(7), 3330-3348.

Fahr, R., \& Irlenbusch, B. (2000). Fairness as a constraint on trust in reciprocity: Earned property rights in a reciprocal exchange experiment. Economics Letters, 66(3), 275282.

Falk, A., \& Ichino, A. (2006). Clean evidence on peer effects. Journal of Labor Economics, 24(1), 39-57.

Fischbacher, U. (2007). z-Tree: Zurich toolbox for ready-made economic experiments. Experimental Economics, 10(2), 171-178.

Frey, B. S., \& Oberholzer-Gee, F. (1997). The cost of price incentives: An empirical analysis of motivation crowding-out. American Economic Review, 87(4), 746-755.

Gächter, S., Huang, L., \& Sefton, M. (2016). Combining "real effort" with induced effort costs: The ball-catching task. Experimental Economics, 19(4), 687-712.

Gill, D., \& Prowse, V. (2012). A structural analysis of disappointment aversion in a real effort competition. American Economic Review, 102(1), 469-503. 
Gneezy, U., Meier, S., \& Rey-Biel, P. (2011). When and why incentives (don't) work to modify behavior. Journal of Economic Perspectives, 25(4), 191-210.

Gneezy, U., Niederle, M., \& Rustichini, A. (2003). Performance in competitive environments: Gender differences. The Quarterly Journal of Economics, 118(3), 1049-1074.

Gneezy, U., \& Potters, J. (1997). An experiment on risk taking and evaluation periods. The Quarterly Journal of Economics, 112(2), 631-645.

Gneezy, U., \& Rustichini, A. (2000). Pay enough or don't pay at all. The Quarterly Journal of Economics, 115(3), 791-810.

Greiner, B. (2015). Subject pool recruitment procedures: Organizing experiments with ORSEE. Journal of the Economic Science Association, 1(1), 114-125.

Hayashi, A. T., Nakamura, B. K., \& Gamage, D. (2013). Experimental evidence of tax salience and the labor-leisure decision: Anchoring, tax aversion, or complexity? Public Finance Review, 41(2), 203-226.

Huxtable, Z. L., White, M. H., \& McCartor, M. A. (1946). A re-performance and reinterpretation of the Arai experiment in mental fatigue with three subjects. Psychological Monographs, 59(5), i-52.

Jenkins, G. D., Jr., Mitra, A., Gupta, N., \& Shaw, J. D. (1998). Are financial incentives related to performance? A meta-analytic review of empirical research. Journal of Applied Psychology, 83(5), 777-787.

Johnson, D., \& Salmon, T. C. (2016). Sabotage versus discouragement: Which dominates post promotion tournament behavior? Southern Economic Journal, 82(3), 673-696.

Kamenica, E. (2012). Behavioral economics and psychology of incentives. Annual Review of Economics, 4, 427-452.

Kessler, J. B., \& Norton, M. I. (2016). Tax aversion in labor supply. Journal of Economic Behavior \& Organization, 124, 15-28.

Konow, J. (2000). Fair shares: Accountability and cognitive dissonance in allocation decisions. American Economic Review, 90(4), 1072-1091.

Kraut, R. E., Sunder, S., Telang, R., \& Morris, J. (2005). Pricing electronic mail to solve the problem of spam. Human-Computer Interaction, 20, 195-223.

Kuhnen, C. M., \& Tymula, A. (2012). Feedback, self-esteem, and performance in organizations. Management Science, 58(1), 94-113.

Kurzban, R., Duckworth, A., Kable, J. W., \& Myers, J. (2013). An opportunity cost model of subjective effort and task performance. Behavioral and Brain Sciences, 36(6), 661-726. 
Lei, V., Noussair, C. N., \& Plott, C. R. (2001). Nonspeculative bubbles in experimental asset markets: Lack of common knowledge of rationality vs. actual irrationality. Econometrica, 69(4), 831-859.

Masclet, D., Peterle, E., \& Larribeau, S. (2015). Gender differences in tournament and flatwage schemes: An experimental study. Journal of Economic Psychology, 47, 103-115.

Mohnen, A., Pokorny, K., \& Sliwka, D. (2008). Transparency, inequity aversion, and the dynamics of peer pressure in teams: Theory and evidence. Journal of Labor Economics, 26(4), 693-720.

Niederle, M., \& Vesterlund, L. (2007). Do women shy away from competition? Do men compete too much? The Quarterly Journal of Economics, 122(3), 1067-1101.

Orne, M. T. (1962). On the social psychology of the psychological experiment: With particular reference to demand characteristics and their implications. American Psychologist, 17(11), 776-783.

Pokorny, K. (2008). Pay—but do not pay too much: An experimental study on the impact of incentives. Journal of Economic Behavior \& Organization, 66(2), 251-264.

Rey-Biel, P., Sheremeta, R. M., \& Uler, N. (2017). When income depends on performance and luck: The effects of culture and information on giving. Working Paper.

Rosaz, J., Slonim, R., \& Villeval, M. C. (2016). Quitting and peer effects at work. Labour Economics, 39, 55-67.

Sheremeta, R. M. (2010). Experimental comparison of multi-stage and one-stage contests. Games and Economic Behavior, 68(2), 731-747.

Takahashi, H., Shen, J., \& Ogawa, K. (2016). An experimental examination of compensation schemes and level of effort in differentiated tasks. Journal of Behavioral and Experimental Economics, 61, 12-19.

van Dijk, F., Sonnemans, J., \& van Winden, F. (2001). Incentive systems in a real effort experiment. European Economic Review, 45(2), 187-214.

Zizzo, D. J. (2010). Experimenter demand effects in economic experiments. Experimental Economics, 13(1), 75-98. 
Figure 1: Screenshot for treatments B, BL, and BH

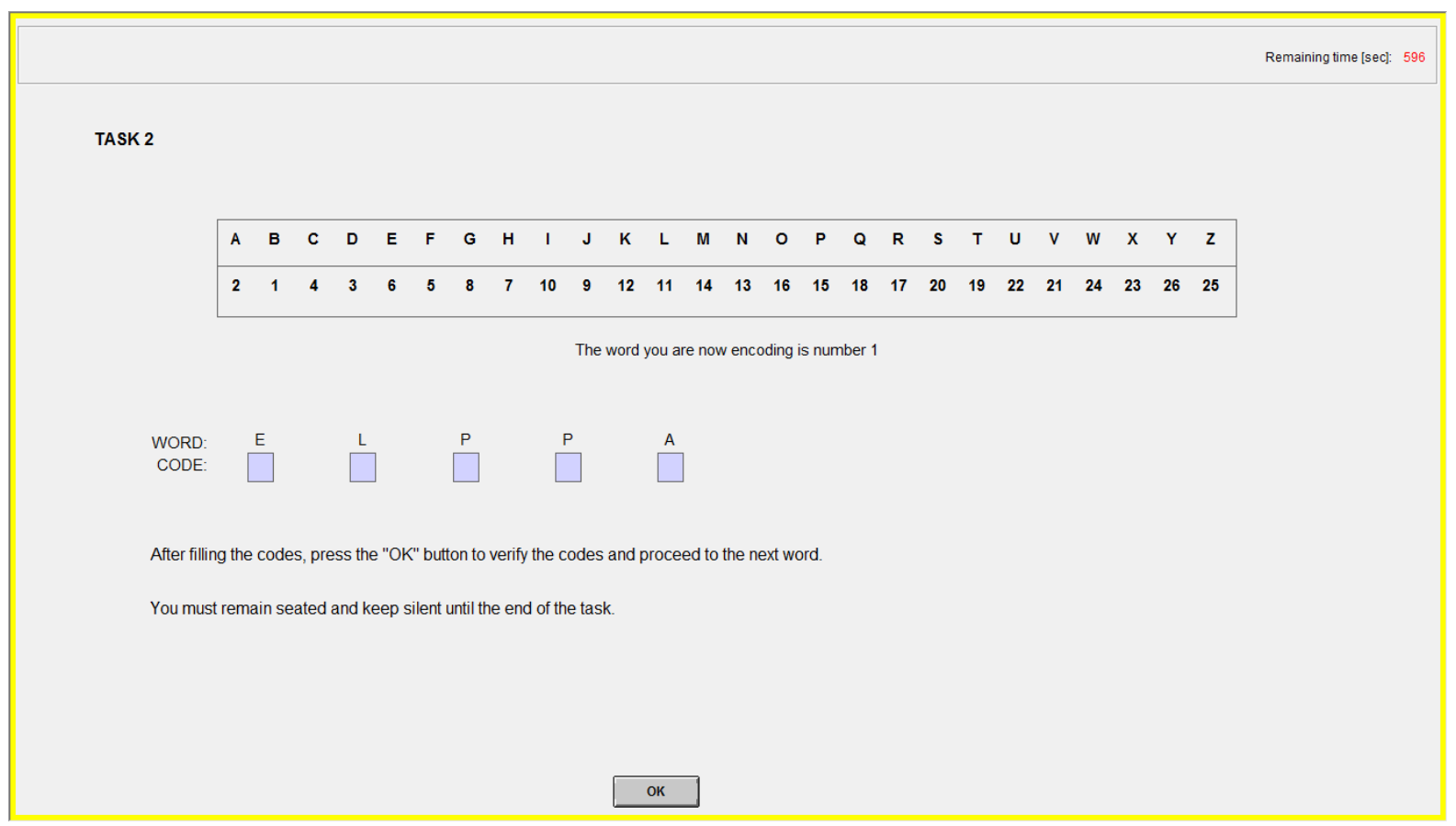


Figure 2: Overall effort choices by treatment (Experiment 1)
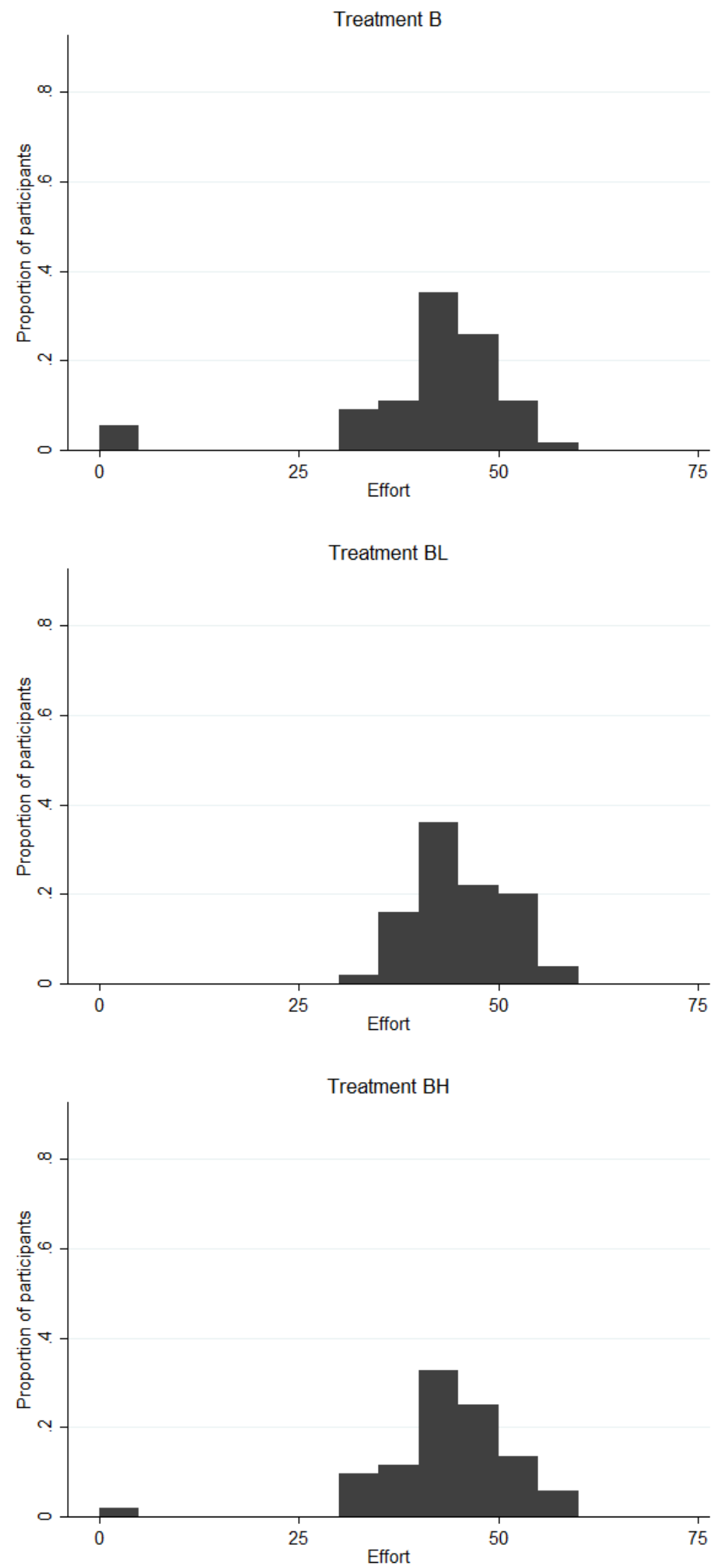
Figure 3: Screenshot for treatments A1A2, A1A2-L, and A1A2-H

Activity 1:

The word you are now encoding is number

$$
\begin{array}{|ccccccccccccccccccccccccccccc}
\hline \text { A } & \text { B } & \text { C } & \text { D } & \text { E } & \text { F } & \text { G } & \text { H } & \text { I } & \text { J } & \text { K } & \text { L } & \text { M } & \text { N } & \text { O } & \text { P } & \text { Q } & \text { R } & \text { S } & \text { T } & \text { U } & \text { V } & \text { W } & \text { X } & \text { Y } & \text { Z } \\
\hline 2 & 1 & 4 & 3 & 6 & 5 & 8 & 7 & 10 & 9 & 12 & 11 & 14 & 13 & 16 & 15 & 18 & 17 & 20 & 19 & 22 & 21 & 24 & 23 & 26 & 25
\end{array}
$$

$\begin{array}{cllll}\text { WORD: } & \mathrm{E} & \mathrm{L} & \mathrm{P} & \mathrm{P} \\ \text { CODE: } & \square & \square & \square\end{array}$

\section{ок}

Activity 2:

$\begin{array}{llllllllllllllllllllllllllll}A & B & C & D & E & F & G & H & \text { I } & \text { J } & \text { K } & \text { L } & \text { M } & \text { N } & \text { O } & \text { P } & \text { Q } & \text { R } & \text { S } & \text { T } & \text { U } & \text { V } & \text { W } & \text { X } & \text { Y } & \text { Z }\end{array}$

$\begin{array}{llllllllllllllllllllllllllllll}26 & 1 & 24 & 3 & 22 & 5 & 20 & 7 & 18 & 9 & 16 & 11 & 14 & 13 & 12 & 15 & 10 & 17 & 8 & 19 & 6 & 21 & 4 & 23 & 2 & 25\end{array}$

$\begin{array}{clllll}\text { WORD: } & \mathrm{R} & \mathrm{E} & \mathrm{P} & \mathrm{A} & \mathrm{P} \\ \text { CODE: } & \square & \square & \square & \square & \square\end{array}$ 
Figure 4: Overall effort choices by treatment (Experiment 2)
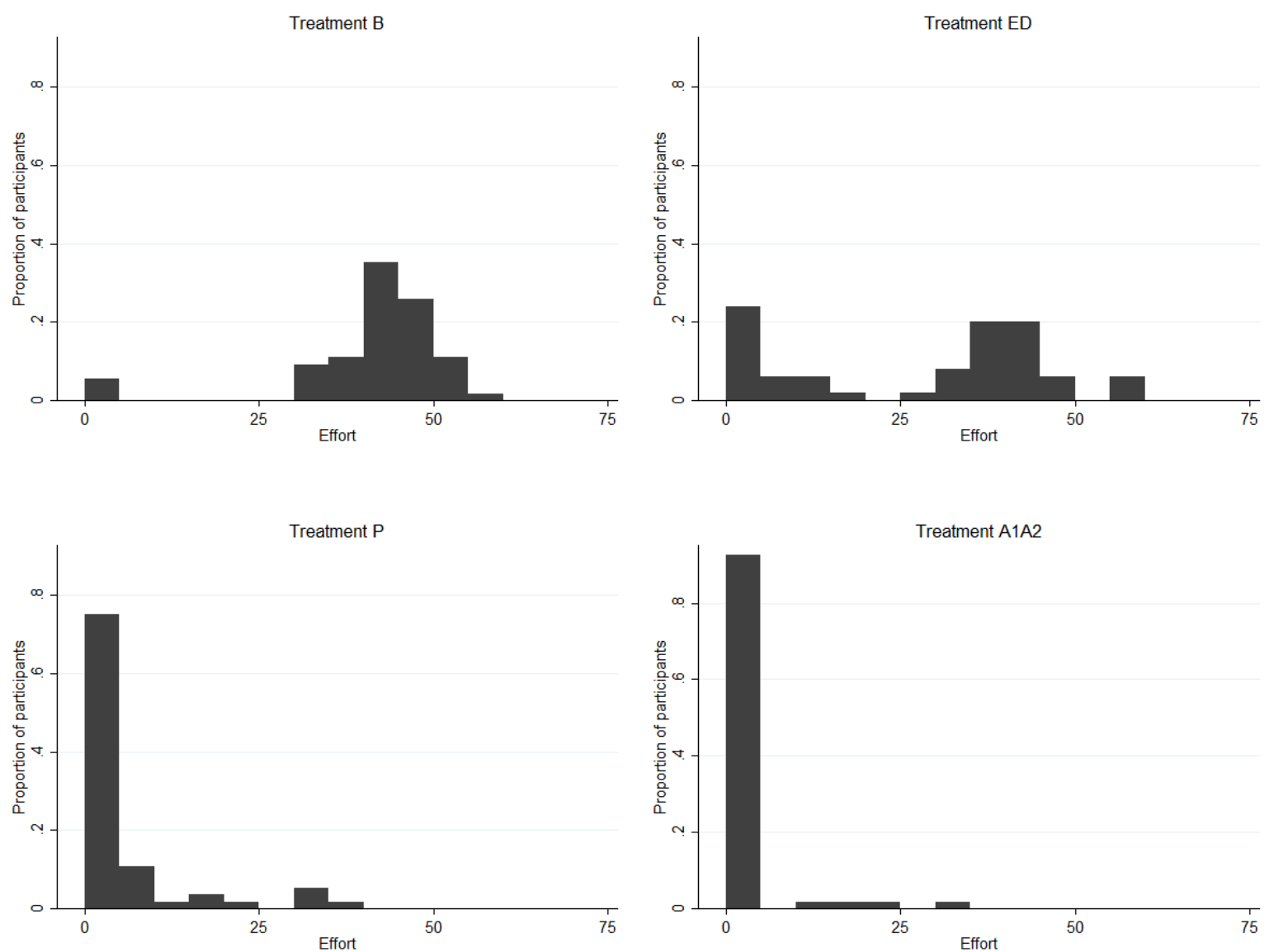

Note: For treatment A1A2, we report the effort exerted in Activity 1. 
Figure 5: Overall effort choices by treatment (Experiment 3)
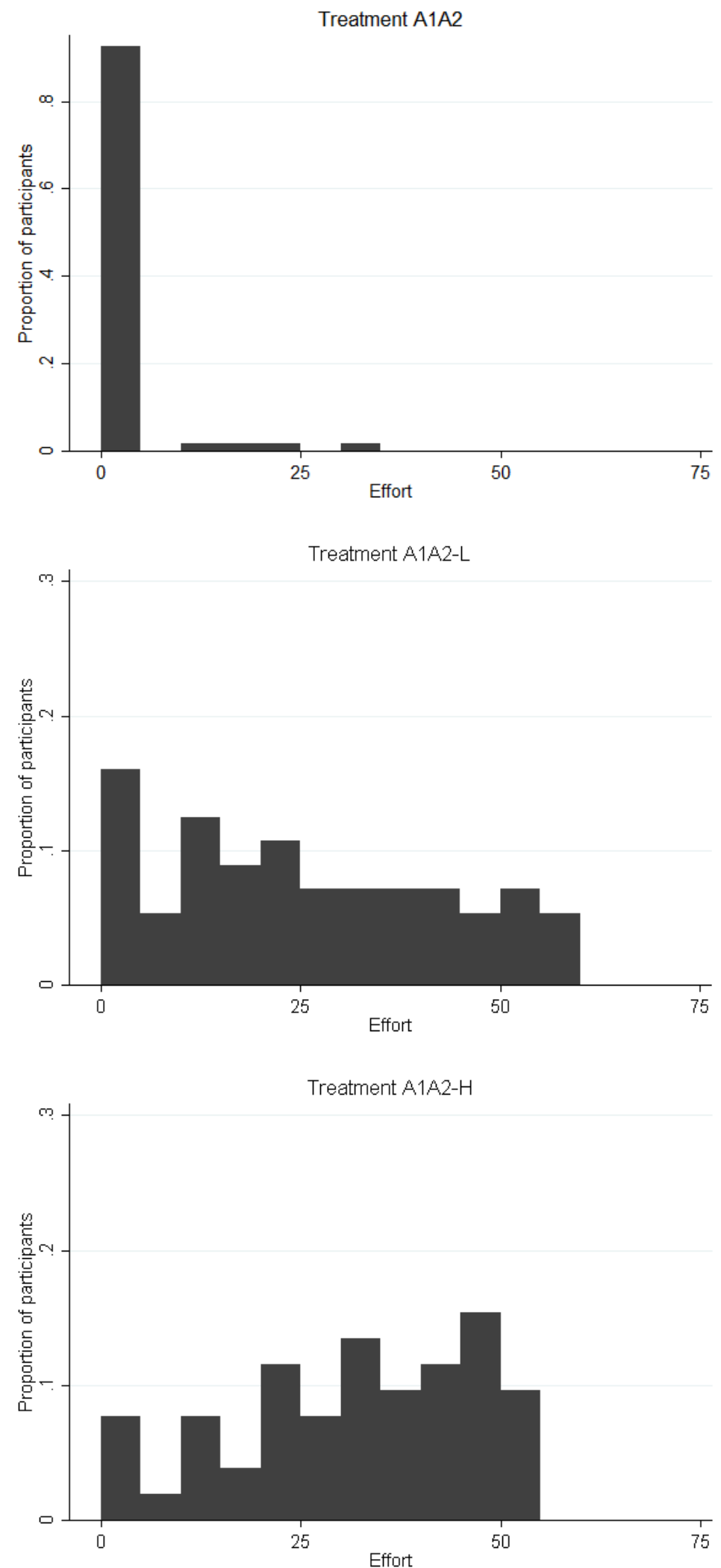

Note: For treatments A1A2, A1A2-L, and A1A2-H, we report the effort exerted in Activity 1. 
Table 1: Summary of experimental treatments

\begin{tabular}{|c|c|c|c|c|}
\hline Treatment & $\begin{array}{c}\text { No. of } \\
\text { subjects }\end{array}$ & $\begin{array}{l}\text { Value of } \\
\text { Prize } 1\end{array}$ & $\begin{array}{l}\text { Value of } \\
\text { Prize } 2\end{array}$ & Features \\
\hline \multicolumn{5}{|l|}{ (a) Experiment 1} \\
\hline Baseline (B) & 54 & $150 \mathrm{ECU}$ & $150 \mathrm{ECU}$ & $\begin{array}{l}\text { Baseline treatment with no } \\
\text { incentives }\end{array}$ \\
\hline Baseline - Low (BL) & 50 & $250 \mathrm{ECU}$ & $150 \mathrm{ECU}$ & $\begin{array}{l}\text { Baseline treatment with low } \\
\text { incentives }\end{array}$ \\
\hline Baseline - High (BH) & 52 & $600 \mathrm{ECU}$ & 150 ECU & $\begin{array}{l}\text { Baseline treatment with high } \\
\text { incentives }\end{array}$ \\
\hline \multicolumn{5}{|l|}{ (b) Experiment 2} \\
\hline Baseline (B) & 54 & $150 \mathrm{ECU}$ & $150 \mathrm{ECU}$ & Baseline treatment \\
\hline Early Departure (ED) & 50 & $150 \mathrm{ECU}$ & $150 \mathrm{ECU}$ & $\begin{array}{l}\text { Outside option: } \\
\text { Can leave experiment early }\end{array}$ \\
\hline Pause (P) & 56 & $150 \mathrm{ECU}$ & $150 \mathrm{ECU}$ & $\begin{array}{l}\text { Outside option: } \\
\text { Timeout payment }\end{array}$ \\
\hline Activity 1/2 (A1A2) & 56 & $150 \mathrm{ECU}$ & $150 \mathrm{ECU}$ & $\begin{array}{l}\text { Outside option: } \\
\text { Same activity with piece rate }\end{array}$ \\
\hline \multicolumn{5}{|l|}{ (c) Experiment 3} \\
\hline Activity 1/2 (A1A2) & 56 & $150 \mathrm{ECU}$ & $150 \mathrm{ECU}$ & $\begin{array}{l}\text { A1A2 treatment with no } \\
\text { incentives }\end{array}$ \\
\hline Activity 1/2 - Low (A1A2-L) & 56 & $250 \mathrm{ECU}$ & $150 \mathrm{ECU}$ & $\begin{array}{l}\text { A1A2 treatment with low } \\
\text { incentives }\end{array}$ \\
\hline Activity 1/2 - High (A1A2-H) & 52 & $600 \mathrm{ECU}$ & $150 \mathrm{ECU}$ & $\begin{array}{l}\text { A1A2 treatment with high } \\
\text { incentives }\end{array}$ \\
\hline
\end{tabular}


Table 2: Summary statistics

\begin{tabular}{|c|c|c|c|}
\hline Treatment & $\#$ of subjects ${ }^{(a)}$ & $\begin{array}{l}\text { Participation } \\
\text { rate }\end{array}$ & $\begin{array}{l}\text { Average effort } \\
\text { per minute }^{(\mathbf{b})}\end{array}$ \\
\hline \multicolumn{4}{|l|}{ (a) Experiment 1} \\
\hline Baseline (B) & 54 & $\begin{array}{c}0.96 \\
{[0.19]}\end{array}$ & $\begin{array}{c}4.22 \\
{[0.81]}\end{array}$ \\
\hline Baseline - Low (BL) & 50 & $\begin{array}{l}1.00 \\
{[0.00]}\end{array}$ & $\begin{array}{c}4.49 \\
{[0.56]}\end{array}$ \\
\hline Baseline - High (BH) & 52 & $\begin{array}{c}1.00 \\
{[0.00]}\end{array}$ & $\begin{array}{c}4.33 \\
{[0.86]}\end{array}$ \\
\hline \multicolumn{4}{|l|}{ (b) Experiment 2} \\
\hline Baseline (B) & 54 & $\begin{array}{c}0.96 \\
{[0.19]}\end{array}$ & $\begin{array}{c}4.22 \\
{[0.81]}\end{array}$ \\
\hline Early Departure (ED) & 50 & $\begin{array}{c}0.82 \\
{[0.39]}\end{array}$ & $\begin{array}{l}3.27 \\
{[1.56]}\end{array}$ \\
\hline Pause (P) & 56 & $\begin{array}{c}0.54 \\
{[0.50]}\end{array}$ & $\begin{array}{c}0.94 \\
{[1.12]}\end{array}$ \\
\hline Activity $1 / 2$ (A1A2) & 53 & $\begin{array}{c}0.38 \\
{[0.49]}\end{array}$ & $\begin{array}{c}0.54 \\
{[0.88]}\end{array}$ \\
\hline \multicolumn{4}{|l|}{ (c) Experiment 3} \\
\hline Activity 1/2 (A1A2) & 53 & $\begin{array}{c}0.38 \\
{[0.49]}\end{array}$ & $\begin{array}{c}0.54 \\
{[0.88]}\end{array}$ \\
\hline Activity 1/2 - Low (A1A2-L) & 56 & $\begin{array}{c}0.98 \\
{[0.13]}\end{array}$ & $\begin{array}{c}2.52 \\
{[1.74]}\end{array}$ \\
\hline Activity 1/2 - High (A1A2-H) & 52 & $\begin{array}{c}0.96 \\
{[0.19]}\end{array}$ & $\begin{array}{c}3.27 \\
{[1.44]}\end{array}$ \\
\hline
\end{tabular}

Sample means given. Standard deviations in brackets.

For treatments A1A2, A1A2-L, and A1A2-H, we report the participation rate and average effort per minute in Activity 1.

(a) We discovered that three subjects in treatment A1A2 had previously participated in the same experiment. Hence, we drop these subjects in our analysis.

(b) Average effort per minute is defined as the average effort by subjects who exerted a positive level of effort. 
Table 3: Regression results for Experiment 1

\begin{tabular}{|c|c|c|c|}
\hline Variables & $\begin{array}{c}\text { Participation =1 } \\
\text { if Effort }>0 \\
(\text { OLS })\end{array}$ & $\begin{array}{c}\text { Effort per minute } \\
\text { given Effort }>0 \\
(\text { OLS })\end{array}$ & $\begin{array}{c}\text { Effort per minute } \\
\text { given Effort }>0 \\
\text { (Quantile) }\end{array}$ \\
\hline & (1) & $(2)$ & (3) \\
\hline Baseline - Low (BL) & $\begin{array}{c}0.032 \\
(0.023)\end{array}$ & $\begin{array}{l}0.329^{* *} \\
(0.133)\end{array}$ & $\begin{array}{c}0.135 \\
(0.157)\end{array}$ \\
\hline Baseline - High (BH) & $\begin{array}{c}0.035 \\
(0.022)\end{array}$ & $\begin{array}{c}0.145 \\
(0.131)\end{array}$ & $\begin{array}{c}0.144 \\
(0.154)\end{array}$ \\
\hline$\%$ invested in risk task & $\begin{array}{l}-0.059 \\
(0.039)\end{array}$ & $\begin{array}{l}-0.296 \\
(0.233)\end{array}$ & $\begin{array}{l}-0.379 \\
(0.275)\end{array}$ \\
\hline Age & $\begin{array}{l}-0.004 \\
(0.003)\end{array}$ & $\begin{array}{l}-0.030^{*} \\
(0.016)\end{array}$ & $\begin{array}{l}-0.023 \\
(0.019)\end{array}$ \\
\hline Female & $\begin{array}{l}-0.003 \\
(0.019)\end{array}$ & $\begin{array}{c}0.068 \\
(0.114)\end{array}$ & $\begin{array}{l}-0.037 \\
(0.134)\end{array}$ \\
\hline Economics major & $\begin{array}{c}0.006 \\
(0.036)\end{array}$ & $\begin{array}{c}-0.938^{* * * *} \\
(0.212)\end{array}$ & $\begin{array}{l}-0.509^{* *} \\
(0.249)\end{array}$ \\
\hline Undergraduate student & $\begin{array}{l}-0.063 \\
(0.098)\end{array}$ & $\begin{array}{l}1.854^{* * *} \\
(0.578)\end{array}$ & $\begin{array}{c}0.282 \\
(0.681)\end{array}$ \\
\hline Graduate student & $\begin{array}{l}-0.045 \\
(0.090)\end{array}$ & $\begin{array}{l}2.094^{* * *} \\
(0.528)\end{array}$ & $\begin{array}{c}0.408 \\
(0.622)\end{array}$ \\
\hline Australian & $\begin{array}{l}-0.031 \\
(0.020)\end{array}$ & $\begin{array}{c}0.188 \\
(0.116)\end{array}$ & $\begin{array}{c}0.157 \\
(0.136)\end{array}$ \\
\hline \# previous experiments & $\begin{array}{c}0.003 \\
(0.005)\end{array}$ & $\begin{array}{c}0.028 \\
(0.031)\end{array}$ & $\begin{array}{c}0.014 \\
(0.036)\end{array}$ \\
\hline Constant & $\begin{array}{l}1.166^{* * *} \\
(0.137)\end{array}$ & $\begin{array}{l}3.060^{* * *} \\
(0.814)\end{array}$ & $\begin{array}{l}4.695^{* * *} \\
(0.958)\end{array}$ \\
\hline Test: & & & \\
\hline $\mathrm{BH}=\mathrm{BL}$ & $\begin{array}{c}0.003 \\
(0.023)\end{array}$ & $\begin{array}{l}-0.184 \\
(0.134)\end{array}$ & $\begin{array}{c}0.010 \\
(0.158)\end{array}$ \\
\hline Observations & 156 & 154 & 154 \\
\hline R-squared & 0.083 & 0.308 & - \\
\hline
\end{tabular}

Ordinary least squares estimates given in (1) and (2), and quantile (median) regression estimates given in (3). Standard errors in parentheses. For all regressions, treatment B is the reference treatment.

In all regressions, the controls are treatment variables and subjects' characteristics, which include the percentage of the endowment invested in the risk task, age, gender, study level at University, whether the subject is pursuing a major in economics, whether the subject is Australian, and previous experience with economic experiments.

${ }^{* * *},{ }^{* *},{ }^{*}$ denote statistical significance at the $1 \%, 5 \%$, and $10 \%$ levels, respectively. 
Table 4: Regression results for Experiment 2

\begin{tabular}{|c|c|c|c|}
\hline \multirow[t]{2}{*}{ Variables } & $\begin{array}{c}\text { Participation }=1 \\
\text { if Effort }>0 \\
(\text { OLS })\end{array}$ & $\begin{array}{l}\text { Effort per minute } \\
\text { given Effort }>0 \\
(\text { OLS })\end{array}$ & $\begin{array}{c}\text { Effort per minute } \\
\text { given Effort >0 } \\
\text { (Quantile) }\end{array}$ \\
\hline & (1) & (2) & (3) \\
\hline Early Departure (ED) & $\begin{array}{l}-0.184^{* *} \\
(0.084)\end{array}$ & $\begin{array}{c}-0.979^{* * *} \\
(0.255)\end{array}$ & $\begin{array}{c}-0.668^{* * *} \\
(0.196)\end{array}$ \\
\hline Pause (P) & $\begin{array}{c}-0.438^{* * *} \\
(0.078)\end{array}$ & $\begin{array}{l}-3.260^{* * *} \\
(0.268)\end{array}$ & $\begin{array}{l}-3.863^{* * *} \\
(0.206)\end{array}$ \\
\hline Activity 1/2 (A1A2) & $\begin{array}{c}-0.596^{* * *} \\
(0.080)\end{array}$ & $\begin{array}{c}-3.778^{* * *} \\
(0.318)\end{array}$ & $\begin{array}{c}-4.111^{* * * *} \\
(0.244)\end{array}$ \\
\hline \% invested in risk task & $\begin{array}{l}-0.226^{* *} \\
(0.107)\end{array}$ & $\begin{array}{l}-0.559 \\
(0.382)\end{array}$ & $\begin{array}{l}-0.063 \\
(0.293)\end{array}$ \\
\hline Age & $\begin{array}{c}0.001 \\
(0.007)\end{array}$ & $\begin{array}{c}0.016 \\
(0.022)\end{array}$ & $\begin{array}{c}0.006 \\
(0.017)\end{array}$ \\
\hline Female & $\begin{array}{l}-0.045 \\
(0.059)\end{array}$ & $\begin{array}{c}0.268 \\
(0.209)\end{array}$ & $\begin{array}{c}0.083 \\
(0.161)\end{array}$ \\
\hline Economics major & $\begin{array}{l}-0.003 \\
(0.092)\end{array}$ & $\begin{array}{c}0.040 \\
(0.331)\end{array}$ & $\begin{array}{l}-0.169 \\
(0.254)\end{array}$ \\
\hline Undergraduate student & $\begin{array}{c}0.038 \\
(0.189)\end{array}$ & $\begin{array}{c}1.008 \\
(0.691)\end{array}$ & $\begin{array}{c}0.759 \\
(0.530)\end{array}$ \\
\hline Graduate student & $\begin{array}{c}0.104 \\
(0.182)\end{array}$ & $\begin{array}{c}1.050 \\
(0.664)\end{array}$ & $\begin{array}{c}0.651 \\
(0.509)\end{array}$ \\
\hline Australian & $\begin{array}{l}-0.150^{* *} \\
(0.061)\end{array}$ & $\begin{array}{c}0.111 \\
(0.225)\end{array}$ & $\begin{array}{c}0.000 \\
(0.173)\end{array}$ \\
\hline \# previous experiments & $\begin{array}{c}0.008 \\
(0.016)\end{array}$ & $\begin{array}{c}0.048 \\
(0.052)\end{array}$ & $\begin{array}{c}0.000 \\
(0.040)\end{array}$ \\
\hline Constant & $\begin{array}{l}1.091^{* * *} \\
(0.281)\end{array}$ & $\begin{array}{l}2.951^{* * *} \\
(0.957)\end{array}$ & $\begin{array}{l}3.448^{* * *} \\
(0.733)\end{array}$ \\
\hline Observations & 213 & 143 & 143 \\
\hline R-squared & 0.290 & 0.651 & - \\
\hline
\end{tabular}

Ordinary least squares estimates given in (1) and (2), and quantile (median) regression estimates given in (3). Standard errors in parentheses. For all regressions, treatment B is the reference treatment.

In all regressions, the controls are treatment variables and subjects' characteristics, which include the percentage of the endowment invested in the risk task, age, gender, study level at University, whether the subject is pursuing a major in economics, whether the subject is Australian, and previous experience with economic experiments.

For treatment A1A2, we consider participation and effort per minute in Activity 1.

${ }^{* * *},{ }^{* *},{ }^{*}$ denote statistical significance at the $1 \%, 5 \%$, and $10 \%$ levels, respectively. 
Table 5: Regression results for Experiment 3

\begin{tabular}{|c|c|c|c|}
\hline Variables & $\begin{array}{c}\text { Participation }=1 \\
\text { if Effort }>0 \\
(\text { OLS })\end{array}$ & $\begin{array}{c}\text { Effort per minute } \\
\text { given Effort }>0 \\
\text { (OLS) }\end{array}$ & $\begin{array}{c}\text { Effort per minute } \\
\text { given Effort }>0 \\
\text { (Quantile) }\end{array}$ \\
\hline & (1) & (2) & (3) \\
\hline Activity 1/2 - Low (A1A2-L) & $\begin{array}{l}0.641^{* * *} \\
(0.063)\end{array}$ & $\begin{array}{l}1.966^{* * *} \\
(0.423)\end{array}$ & $\begin{array}{l}1.934^{* * *} \\
(0.664)\end{array}$ \\
\hline Activity 1/2 - High (A1A2-H) & $\begin{array}{l}0.603^{* * *} \\
(0.064)\end{array}$ & $\begin{array}{l}2.884^{* * *} \\
(0.417)\end{array}$ & $\begin{array}{l}3.280^{* * *} \\
(0.655)\end{array}$ \\
\hline$\%$ invested in risk task & $\begin{array}{l}-0.126 \\
(0.106)\end{array}$ & $\begin{array}{l}1.291^{* *} \\
(0.592)\end{array}$ & $\begin{array}{l}1.052 \\
(0.929)\end{array}$ \\
\hline Age & $\begin{array}{l}0.015^{*} \\
(0.009)\end{array}$ & $\begin{array}{c}0.078 \\
(0.049)\end{array}$ & $\begin{array}{c}0.078 \\
(0.077)\end{array}$ \\
\hline Female & $\begin{array}{l}-0.054 \\
(0.056)\end{array}$ & $\begin{array}{l}-0.163 \\
(0.309)\end{array}$ & $\begin{array}{l}-0.365 \\
(0.485)\end{array}$ \\
\hline Economics major & $\begin{array}{l}-0.023 \\
(0.083)\end{array}$ & $\begin{array}{l}-0.405 \\
(0.455)\end{array}$ & $\begin{array}{l}-0.250 \\
(0.715)\end{array}$ \\
\hline Undergraduate student & $\begin{array}{l}-0.015 \\
(0.229)\end{array}$ & $\begin{array}{l}-0.773 \\
(1.093)\end{array}$ & $\begin{array}{c}0.016 \\
(1.717)\end{array}$ \\
\hline Graduate student & $\begin{array}{l}-0.007 \\
(0.235)\end{array}$ & $\begin{array}{l}-1.254 \\
(1.124)\end{array}$ & $\begin{array}{l}-0.533 \\
(1.765)\end{array}$ \\
\hline Australian & $\begin{array}{l}-0.021 \\
(0.056)\end{array}$ & $\begin{array}{c}0.169 \\
(0.302)\end{array}$ & $\begin{array}{c}0.183 \\
(0.474)\end{array}$ \\
\hline \# previous experiments & $\begin{array}{l}-0.007 \\
(0.014)\end{array}$ & $\begin{array}{l}-0.067 \\
(0.073)\end{array}$ & $\begin{array}{l}-0.059 \\
(0.115)\end{array}$ \\
\hline Constant & $\begin{array}{c}0.164 \\
(0.319)\end{array}$ & $\begin{array}{l}-0.903 \\
(1.658)\end{array}$ & $\begin{array}{l}-1.632 \\
(2.604)\end{array}$ \\
\hline $\begin{array}{l}\text { Test: } \\
\text { A1A2-H = A1A2-L }\end{array}$ & $\begin{array}{l}-0.038 \\
(0.062)\end{array}$ & $\begin{array}{l}0.918^{* * *} \\
(0.303)\end{array}$ & $\begin{array}{l}1.345^{* * *} \\
(0.475)\end{array}$ \\
\hline Observations & 161 & 125 & 125 \\
\hline R-squared & 0.477 & 0.352 & - \\
\hline
\end{tabular}

Ordinary least squares estimates given in (1) and (2), and quantile (median) regression estimates given in (3). Standard errors in parentheses. For all regressions, treatment A1A2 is the reference treatment.

In all regressions, the controls are treatment variables and subjects' characteristics, which include the percentage of the endowment invested in the risk task, age, gender, study level at University, whether the subject is pursuing a major in economics, whether the subject is Australian, and previous experience with economic experiments.

For treatments A1A2, A1A2-L, and A1A2-H, we consider participation and effort per minute in Activity 1.

${ }^{* * *},{ }^{* *},{ }^{*}$ denote statistical significance at the $1 \%, 5 \%$, and $10 \%$ levels, respectively. 


\section{Online Appendix}

\section{Appendix A: Experimental instructions}

This section contains the instructions. Task 1 is the risk task which was common to all treatments. Task 2 is the contest task which differed between treatments. We provide the instructions for Task 2 which were used in treatments B and A1A2. Instructions for the other treatments were appropriately adjusted and are available from the authors upon request. ${ }^{23}$

${ }^{23}$ For the reviewers' convenience, the instructions for Task 2 of treatments ED and P are included in a separate document as part of the submission. 


\section{Instructions}

Thank you for agreeing to take part in this study which is funded by the Australian Research Council. Please read the following instructions carefully. A clear understanding of the instructions will help you make better decisions and increase your earnings from the experiment.

The experiment consists of two separate tasks: Task 1 and Task 2. You will receive detailed instructions about each of the tasks before you participate in them. Note that the tasks are independent of each other. Your earnings will depend on the decisions you make in one of the two tasks. In other words, you will be paid for the decisions you make in either Task 1 or Task 2 . This implies that you should carefully consider all of the decisions you make in both tasks in the experiment as they may determine your earnings. Whether you will be paid for Task 1 or Task 2 will be randomly determined at the end of the experiment using a coin toss. Your final payment in today's experiment will also include a \$10 participation fee.

During the experiment, we will be using Experimental Currency Units (ECU). At the end of the experiment, we will convert the amount you earn into Australian Dollars (AUD) using the following conversion rate: $10 \mathrm{ECU}=1$ AUD.

All of the decisions you make in this experiment will remain anonymous. At the end of Task 2, you will be asked to fill out a brief questionnaire asking you some general questions.

Please do not talk to one another during the experiment. If you have any questions, please raise your hand and we will come over to answer your questions privately. 


\section{Task 1}

In this task, you will be given an endowment of 50 ECU. You have the opportunity to invest any portion of this amount (i.e., any amount between 0 and 50).

The investment can either fail or succeed. There is an equal chance that the investment will fail or succeed. If the investment fails, you will lose the amount you invested. If the investment succeeds, you will receive three times the amount invested. Whether an investment fails or succeeds will be determined by the computer.

You will be given an on-screen calculator that you can use to calculate the amount you would be paid if your investment is successful and if it is not. Figure 1 shows the decision screen for this task, where the calculator is on the left panel. You can submit your actual investment decision at the bottom of the screen. After you choose how much you wish to invest, please press the submit button.

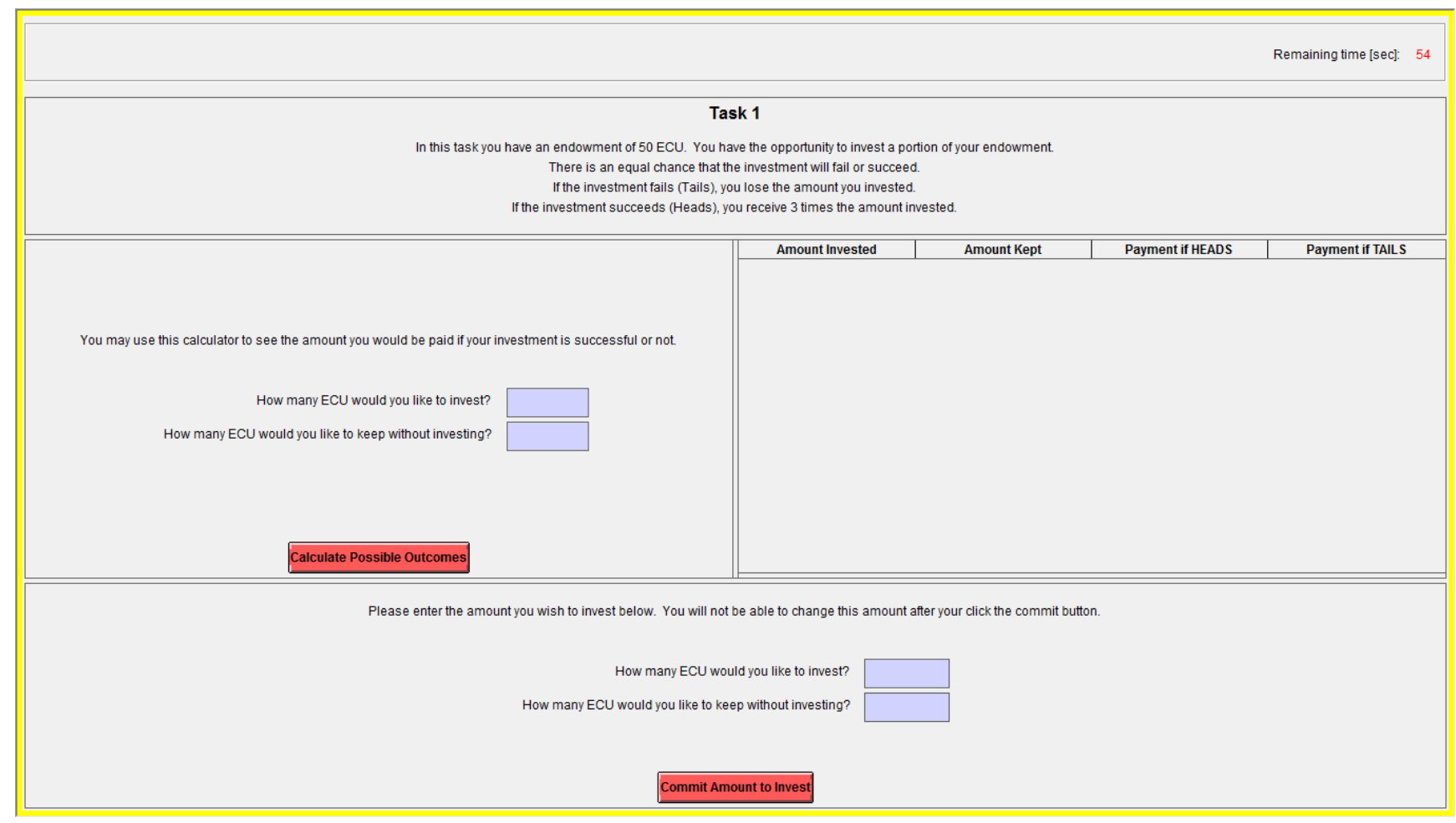

Figure 1: Decision Screen for Task 1

If this task is picked for payment, the computer will determine randomly whether your investment succeeds or fails. 
Here are some examples:

1. Suppose you choose to invest nothing. You will get 50 ECU for sure from this task if this task is chosen for payment.

2. Suppose you choose to invest all of the endowment, i.e., 50 ECU. If the investment succeeds, you get 150 ECU. If the investment fails, you get 0 .

3. Suppose you choose to invest 40 ECU. If the investment succeeds, you get 130 ECU ( $40 \times 3+10$ =130). If it fails, you get 10 ECU.

If you have any questions, please raise your hand. If not, please proceed to make your decision on the computer screen. 


\section{Task 2 (Treatment B)}

In this task, the computer will randomly match you with one other person in the room. Hence, you will participate in Task 2 in groups of two. No one will ever be informed of the identity of the other individual in their group.

Each group member will have one of two possible roles: Player A or Player B. At the beginning of the task, you will be informed whether you have been assigned the role of Player A or Player B. Each individual in your group has an equal chance of being assigned the role of Player A or Player B.

Player A and Player B will be given the opportunity to participate in an activity. The activity is the same for both players. Player A and Player B will each be presented with a series of words. They will be asked to encode these words by substituting the letters of the alphabet with numbers using an encoding table which will be provided on their screens. Every time a word is encoded correctly, the encoding table will change.

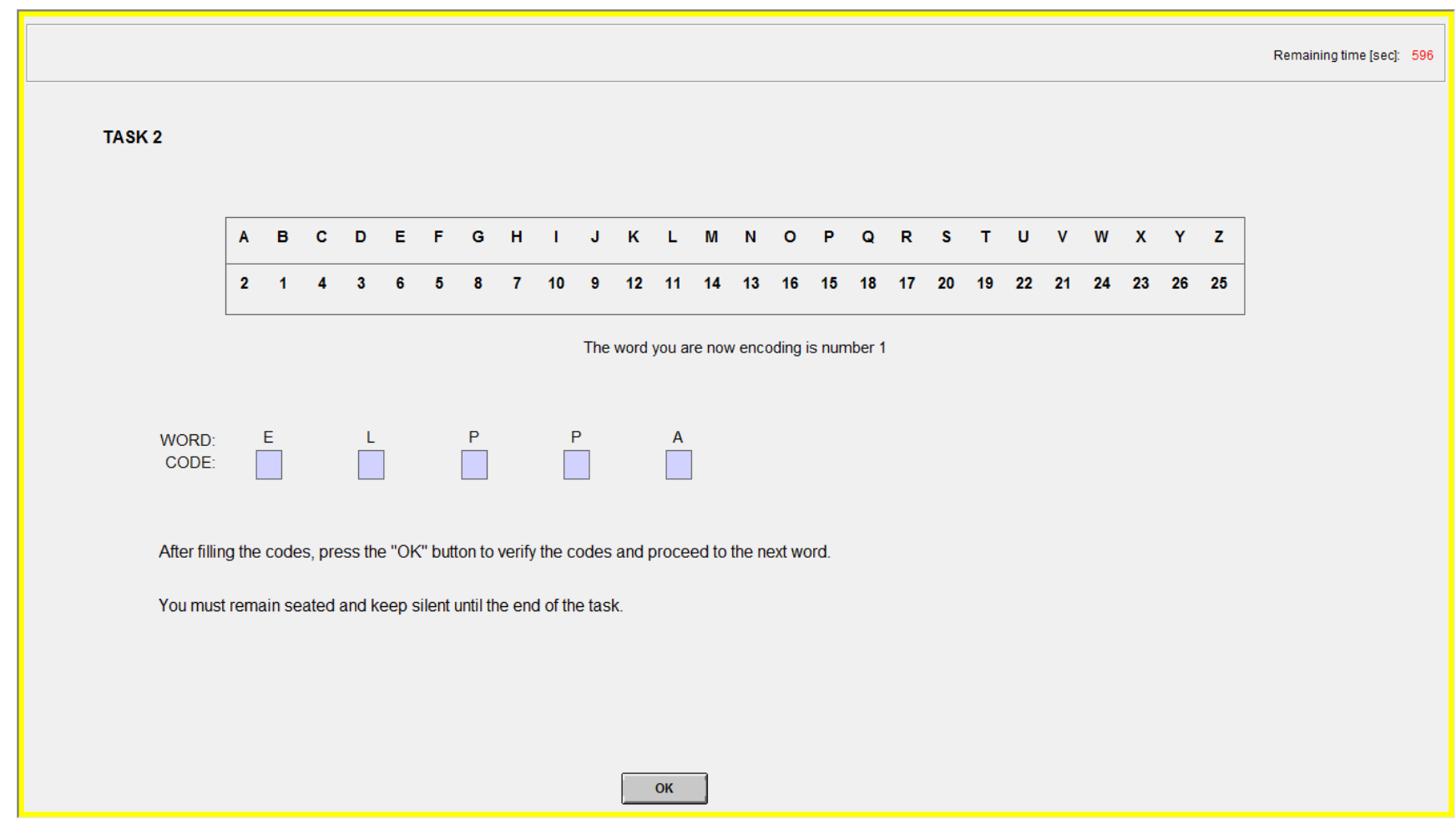

Figure 2: Encoding Activity for Task 2

Once you encode a word correctly, the computer will prompt you with another word which you will be asked to encode. Once you encode that word, you will be given another word and so on. This process will continue for 10 minutes (600 seconds). Player A and Player B will be given the same words to encode in the same sequence. 
Figure 2 shows an example of a word (ELPPA) to be encoded. The table given on the screen shows that $\mathrm{E}=6, \mathrm{~L}=11, \mathrm{P}=15, \mathrm{P}=15$, and $\mathrm{A}=2$.

There are two prizes, Prize 1 and Prize 2. These two prizes will be allocated to Player A and Player B according to the total number of words correctly encoded by the players.

The number of words encoded correctly by the players in the 10-minute period will determine who receives Prize 1 . The player who does not receive Prize 1 will receive Prize 2 . Prize 1 is worth 150 ECU. Prize 2 is worth 150 ECU.

Given the number of words correctly encoded by Player A and Player B, Prize 1 will be allocated in the following manner.

You can never guarantee yourself Prize 1. However, by encoding more words correctly, you can increase your chance of receiving Prize 1. The more words you encode relative to the other player, the greater your chance of receiving Prize 1 . The more words the other player encodes, the less likely you are to receive Prize 1 . Specifically, your chance of receiving Prize 1 is given by the following expression.

$$
\begin{aligned}
& \text { Your chance of receiving Prize } 1 \\
& \qquad=\frac{\# \text { words you encode correctly }}{\# \text { words you encode correctly }+\# \text { words the other player encodes correctly }}
\end{aligned}
$$

You can think of it in the following way. For example, if you encode 10 words correctly in total and the other player encodes 20 words correctly in total, then you will receive 10 lottery tickets while the other participant will receive 20 lottery tickets. At the end of Task 2, the computer randomly draws one of the 30 lottery tickets received by you and the other player. The owner of the drawn ticket receives Prize 1. In this example, your chance of receiving Prize 1 is $10 /(10+20)=0.33$ and the other participant's chance of receiving Prize 1 is $20 /(10+20)=0.67$. Hence, your chance of receiving Prize 1 depends on the number of lottery tickets received by you and the other participant. The player who does not receive Prize 1 will receive Prize 2. If both Player A and Player B encode the same number of words correctly, then the computer will allocate the two prizes randomly. Each player has the same chance of receiving Prize 1.

If you have any questions, please raise your hand. Otherwise, please proceed to answer the questions on the next page. The purpose of these questions is to make sure that you understand the task. Any unclear points will be explained by the experimenter. Once you have answered all the questions, please raise your hand and one of the experimenters will come to check your answers. We will proceed with the task after checking everyone's answers. 


\section{Practice Questions for Task 2}

(Please note that the numbers in the following questions are for illustration purposes only. The questions aim to help you understand the task in a better way and should not be used as a guide for decision-making in the experiment.)

1. Assume that you encode 1 word and your opponent encodes 9 words. What is your chance of receiving Prize 1 ?
(a) $1 / 9$
(b) $1 / 10$
(c) $1 / 8$
(d) $8 / 9$
(e) $9 / 10$

2. Assume that you encode 9 words and your opponent encodes 1 word. What is your chance of receiving Prize 1 ?
(a) $1 / 9$
(b) $1 / 10$
(c) $8 / 9$
(d) $9 / 10$
(e) $9 / 9$

3. Assume that Player A encodes 45 words. State whether each of the following statements is true or false.

(i) If Player B encodes 0 words, then Player B will definitely receive Prize 2 which is worth 150 ECU.

(ii) If Player B encodes 1 word, then Player B will definitely receive Prize 2 which is worth 150 ECU.

(iii) If Player B encodes 45 words, then each player will receive Prize 2 which is worth 150 ECU. 


\section{Important summary information:}

- Task 2 is played in groups of two. The matchings are anonymous. You will not be told which of the participants in this room are assigned to which group.

- Player A and Player B will be given the opportunity to participate in an activity to encode words using the codes given on the screen.

- There are two prizes in this task - Prize 1 and Prize 2. You can never guarantee yourself Prize 1. However, by encoding more words correctly, you can increase your chance of receiving Prize 1. The player who does not receive Prize 1 receives Prize 2. Prize 1 is worth 150 ECU. Prize 2 is worth 150 ECU.

If you have no further questions, we will now begin a practice round of the activity. The practice round will last for 3 minutes (180 seconds). The purpose of the practice round is for you to familiarise yourself with the activity. The number of words you encode during this practice round will not affect your payment in today's experiment.

Once you have completed the practice round, the computer will reveal the information about your assigned role for Task 2. Task 2 will then begin. 


\section{Task 2 (Treatment A1A2)}

In this task, each player will have a choice between two activities: Activity 1 or Activity 2. You may choose to do only one, both, or none of the activities. At any time during the task, you can switch between the two activities as many times as you want. Your payment from this task will be equal to the total earnings that you receive from both Activity 1 and Activity 2. You will be given 10 minutes (600 seconds) to participate in both activities.

A screenshot of both activities is shown in Figure 2. Activity 1 is located in the top panel with a blue frame, while Activity 2 is located in the bottom panel with a red frame.

Activity 1:

The word you are now encoding is number 1

\begin{tabular}{|cccccccccccccccccccccccccccc}
\hline A & B & C & D & E & F & G & H & I & J & K & L & M & N & O & P & Q & R & S & T & U & V & W & X & Y & Z \\
\hline 2 & 1 & 4 & 3 & 6 & 5 & 8 & 7 & 10 & 9 & 12 & 11 & 14 & 13 & 16 & 15 & 18 & 17 & 20 & 19 & 22 & 21 & 24 & 23 & 26 & 25 &
\end{tabular}

$\begin{array}{lllll}\text { WORD: } & \mathrm{E} & \mathrm{L} & \mathrm{P} & \mathrm{P} \\ \text { CODE: } & \square & \square & \square\end{array}$

Activity 2:

Figure 2: Encoding Activities for Task 2 


\section{Activity 1}

To participate in Activity 1, the computer will randomly match you with one other person in the room. No one will ever be informed of the identity of the other individual in their group. Each group member will have one of two possible roles: Player A or Player B. At the beginning of the task, you will be informed whether you have been assigned the role of Player A or Player B. Each individual in your group has an equal chance of being assigned the role of Player A or Player B.

Player A and Player B will each be presented with a series of words in the same order. They will be asked to encode these words by substituting the letters of the alphabet with numbers using an encoding table which will be provided on their screens. Every time a word is encoded correctly, the encoding table will change.

As an example, Figure 2 shows that in Activity 1, the word to be encoded is ELPPA, and the table given on the screen shows that $\mathrm{E}=6, \mathrm{~L}=11, \mathrm{P}=15, \mathrm{P}=15$, and $\mathrm{A}=2$.

Once you encode a word correctly, the computer will prompt you with another word which you will be asked to encode. Once you encode that word, you will be given another word and so on.

There are two prizes, Prize 1 and Prize 2. These two prizes will be allocated to Player A and Player B according to the total number of words correctly encoded by the players.

The number of words encoded correctly by the players in the 10-minute period will determine who receives Prize 1 . The player who does not receive Prize 1 will receive Prize 2 in Activity 1 . Prize 1 is worth 150 ECU. Prize 2 is worth 150 ECU.

Given the number of words correctly encoded by Player A and Player B in Activity 1, Prize 1 will be allocated in the following manner.

You can never guarantee yourself Prize 1. However, by encoding more words correctly in Activity 1, you can increase your chance of receiving Prize 1. The more words you encode relative to the other player, the greater your chance of receiving Prize 1. The more words the other player encodes, the less likely you are to receive Prize 1 . Specifically, your chance of receiving Prize 1 is given by the following expression.

$$
\begin{aligned}
& \text { Your chance of receiving Prize } 1 \text { in Activity } 1 \\
& =\frac{\# \text { words you encode in Activity } 1}{\# \text { words you encode in Activity } 1+\# \text { words the other player encodes in Activity } 1}
\end{aligned}
$$

You can think of it in the following way. For example, if you encode 10 words correctly in total and the other player encodes 20 words correctly in total, then you will receive 10 lottery tickets while the 
other participant will receive 20 lottery tickets. At the end of Task 2, the computer randomly draws one of the 30 lottery tickets received by you and the other player. The owner of the drawn ticket receives Prize 1. In this example, your chance of receiving Prize 1 is $10 /(10+20)=0.33$ and the other participant's chance of receiving Prize 1 is $20 /(10+20)=0.67$. Hence, your chance of receiving Prize 1 depends on the number of lottery tickets received by you and the other participant. The player who does not receive Prize 1 will receive Prize 2. If both Player A and Player B encode the same number of words correctly, then the computer will allocate the two prizes randomly. Each player has the same chance of receiving Prize 1.

\section{Activity 2}

The task in Activity 2 is the same. However, you participate in this activity individually and your payment is determined differently.

Specifically, inn Activity 2, you will receive 1.25 ECU for each word that you encode correctly. Hence, if you encode 4 words correctly in Activity 2, then you will receive 5 ECU from this activity.

In both Activity 1 and Activity 2, all participants will be given the same encoding tables and the same words in the same order. However, the encoding tables and the sequence of words will be different between the two activities. As an example, Figure 2 shows that while the word is ELPPA in Activity 1 , it is REPAP in Activity 2. The table given on the screen shows that $R=17, E=22, P=15, A=26$, and $\mathrm{P}=15$.

At the end of the experiment, if Task 2 is picked for payment, then you will receive:

Payment for Task 2 = (Prize 1 or Prize 2$)+($ number of words you encode in Activity 2 x 1.25 ECU).

If you have any questions, please raise your hand. Otherwise, please proceed to answer the questions on the next page. The purpose of these questions is to make sure that you understand the task. Any unclear points will be explained by the experimenter. Once you have answered all the questions, please raise your hand and one of the experimenters will come to check your answers. We will proceed with the task after checking everyone's answers. 


\section{Practice Questions for Task 2}

(Please note that the numbers in the following questions are for illustration purposes only. The questions aim to help you understand the task in a better way and should not be used as a guide for decision-making in the experiment.)

1. In Activity 1, assume that you encode 1 word and your opponent encodes 9 words. What is your chance of receiving Prize 1 ?
(a) $1 / 9$
(b) $1 / 10$
(c) $1 / 8$
(d) $8 / 9$
(e) $9 / 10$

2. In Activity 1, assume that you encode 9 words and your opponent encodes 1 word. What is your chance of receiving Prize 1 ?
(a) $1 / 9$
(b) $1 / 10$
(c) $8 / 9$
(d) $9 / 10$
(e) $9 / 9$

3. In Activity 1, assume that Player A encodes 45 words. State whether each of the following statements is true or false.

(i) If Player B encodes 0 words in Activity 1, then Player B will definitely receive Prize 2 which is worth $150 \mathrm{ECU}$.

(ii) If Player B encodes 1 word in Activity 1, then Player B will definitely receive Prize 2 which is worth $150 \mathrm{ECU}$.

(iii) If Player B encodes 45 words in Activity 1, then each player will receive Prize 2 which is worth 150 ECU.

4. Suppose you encode 20 words correctly in Activity 1, and 40 words correctly in Activity 2. Suppose also that Player B encodes 20 words correctly in Activity 1. What would be the total payment you can receive from this task?
(a) $40 \mathrm{ECU}$
(b) $60 \mathrm{ECU}$
(c) $75 \mathrm{ECU}$
(d) $150 \mathrm{ECU}$
(e) $200 \mathrm{ECU}$ 
5. Suppose you encode 0 words correctly in Activity 1, and 40 words correctly in Activity 2. Suppose also that Player B encodes 20 words correctly in Activity 1 . What would be the total payment you can receive from this task?

(a) 40 ECU

(b) $60 \mathrm{ECU}$

(c) $75 \mathrm{ECU}$

(d) $150 \mathrm{ECU}$

(e) $200 \mathrm{ECU}$ 


\section{Important summary information:}

- In Task 2, there are two activities. You may choose to do only one, both, or none of the activities. At any time during the task, you can switch between the two activities as many times as you want.

- Activity 1 is played in groups of two. The matchings are anonymous. You will not be told which of the participants in this room are assigned to which group.

- Activity 2 is played individually.

- In each activity, you will be asked to encode words using the codes given on the screen.

- Your payment from this task will be equal to the total earnings that you receive from both Activity 1 and Activity 2.

- In Activity 1, there are two prizes- Prize 1 and Prize 2. You can never guarantee yourself Prize 1. However, by encoding more words correctly, you can increase your chance of receiving Prize 1. The player who does not receive Prize 1 receives Prize 2. Prize 1 is worth 150 ECU. Prize 2 is worth 150 ECU.

- In Activity 2, you will receive 1.25 ECU for each word that you encode correctly.

If you have no further questions, we will now begin a practice round of the activities. The practice round will last for 3 minutes (180 seconds). The purpose of the practice round is for you to familiarise yourself with both activities. The number of words you encode in both activities during this practice round will not affect your payment in today's experiment.

Once you have completed the practice round, the computer will reveal the information about your assigned role for Task 2. Task 2 will then begin. 


\section{Appendix B: Additional analysis}

In this section, we present the analysis including three additional treatments: (i) Slider (S); (ii) 20-Minute (20-Min); and (iii) Effort Choice (EC). We show that the main results in the paper continue to hold after the inclusion of the data from these treatments.

Table B1 presents a summary of all the treatments including these three additional treatments. Figure B1 presents histograms of the distribution of effort in these additional treatments.

Data from these three treatments are pooled together with the data from Experiment 2, and Table B2 presents the participation rate and average effort per minute conditional on participation in these treatments. Table B3 presents the results of OLS and quantile (median) regressions of participation (column 1) and effort per minute (columns 2 and 3) for Experiment 2 including these additional treatments.

A comparison of treatments S and 20-Min to treatment B reveals that, in the absence of monetary incentives, both participation and effort per minute remain very high even when a different task is used or when the duration of the task is increased. $94 \%$ and $92 \%$ of the subjects exert positive effort in treatments S and 20-Min, respectively. These participation rates are not significantly different from that in treatment B (Fisher's exact tests, B vs. S: p-value $=0.678$; B vs. 20-Min: $\mathrm{p}$-value $=0.433$ ). The average effort per minute in treatment 20-Min is 4.22 , which is also not significantly different to that in treatment B (Wilcoxon rank-sum test, B vs. 20-Min: $\mathrm{p}$-value $=0.959) .{ }^{24}$ The regression estimates in Table B3 are also consistent with these findings.

Finally, we find that the behavior of the subjects in treatment EC is largely similar to that in Activity 1 of treatment A1A2. 36\% of subjects exert positive effort in treatment EC, and this

\footnotetext{
${ }^{24}$ We do not compare the average effort per minute between treatments B and S since the tasks used in these treatments are different.
} 
is not statistically different to that in treatment A1A2 (Fisher's exact test, A1A2 vs. EC: pvalue $=1.000$ ). This suggests that competitiveness is a key driver of effort for some subjects who choose to exert effort even in the absence of monetary prizes. This result is also consistent with Sheremeta (2010). 
Figure B1: Overall effort choices by treatment (S, 20-Min, and EC)
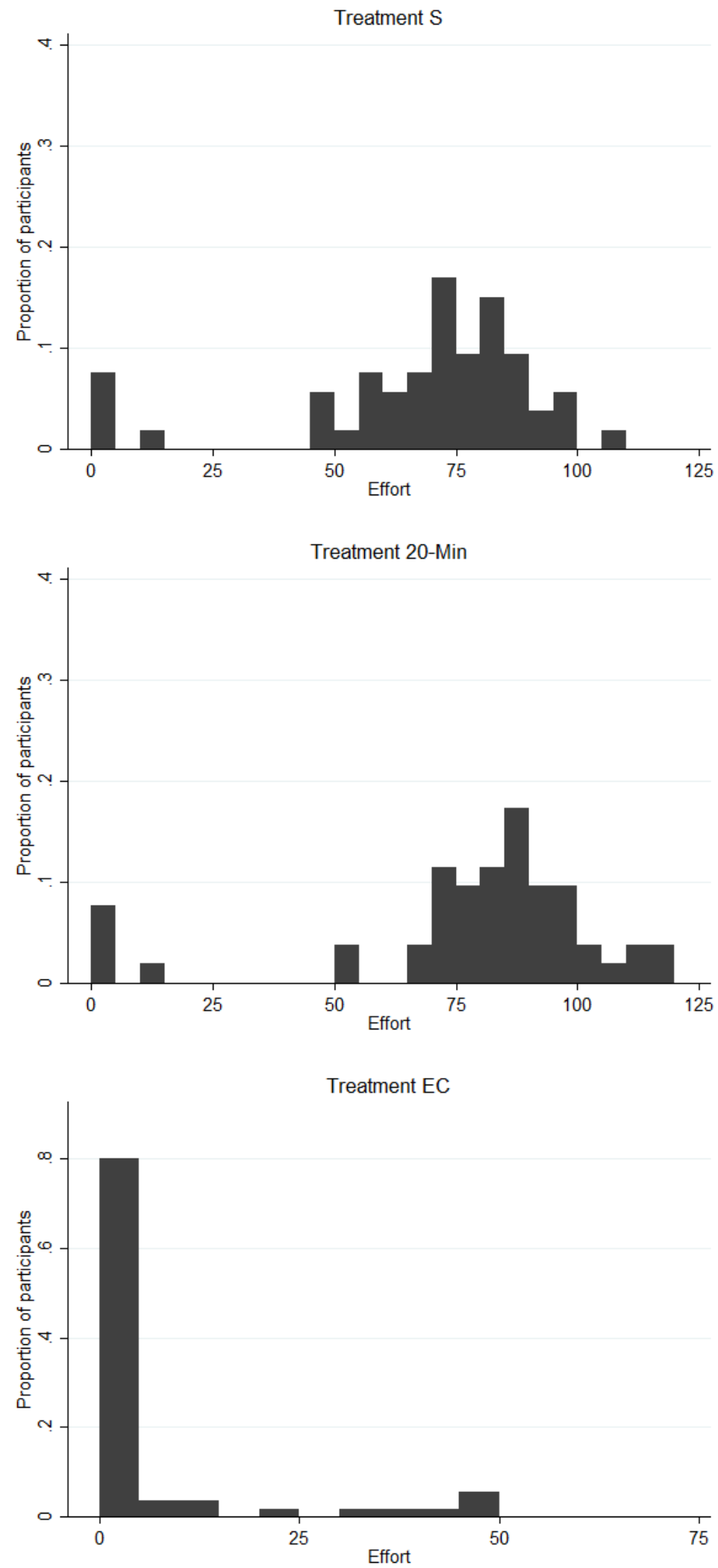
Table B1: Summary of experimental treatments (including treatments S, 20-Min, and EC)

\begin{tabular}{|c|c|c|c|c|}
\hline Treatment & $\begin{array}{c}\text { No. of } \\
\text { subjects }\end{array}$ & $\begin{array}{l}\text { Value of } \\
\text { Prize } 1\end{array}$ & $\begin{array}{l}\text { Value of } \\
\text { Prize } 2\end{array}$ & Features \\
\hline \multicolumn{5}{|l|}{ (a) Experiment 1} \\
\hline Baseline (B) & 54 & $150 \mathrm{ECU}$ & $150 \mathrm{ECU}$ & $\begin{array}{l}\text { Baseline treatment with no } \\
\text { incentives }\end{array}$ \\
\hline Baseline - Low (BL) & 50 & $250 \mathrm{ECU}$ & $150 \mathrm{ECU}$ & $\begin{array}{l}\text { Baseline treatment with low } \\
\text { incentives }\end{array}$ \\
\hline Baseline - High (BH) & 52 & $600 \mathrm{ECU}$ & 150 ECU & $\begin{array}{l}\text { Baseline treatment with high } \\
\text { incentives }\end{array}$ \\
\hline \multicolumn{5}{|l|}{ (b) Experiment 2} \\
\hline Baseline (B) & 54 & $150 \mathrm{ECU}$ & $150 \mathrm{ECU}$ & Baseline treatment \\
\hline Early Departure (ED) & 50 & $150 \mathrm{ECU}$ & $150 \mathrm{ECU}$ & $\begin{array}{l}\text { Outside option: } \\
\text { Can leave experiment early }\end{array}$ \\
\hline Pause (P) & 56 & $150 \mathrm{ECU}$ & $150 \mathrm{ECU}$ & $\begin{array}{l}\text { Outside option: } \\
\text { Timeout payment }\end{array}$ \\
\hline Activity 1/2 (A1A2) & 56 & $150 \mathrm{ECU}$ & $150 \mathrm{ECU}$ & $\begin{array}{l}\text { Outside option: } \\
\text { Same activity with piece rate }\end{array}$ \\
\hline Slider (S) & 54 & $150 \mathrm{ECU}$ & $150 \mathrm{ECU}$ & Slider task used \\
\hline 20-Minute (20-Min) & 56 & $150 \mathrm{ECU}$ & $150 \mathrm{ECU}$ & Longer duration \\
\hline Effort Choice (EC) & 56 & $150 \mathrm{ECU}$ & $150 \mathrm{ECU}$ & No real-effort task \\
\hline \multicolumn{5}{|l|}{ (c) Experiment 3} \\
\hline Activity 1/2 (A1A2) & 56 & $150 \mathrm{ECU}$ & $150 \mathrm{ECU}$ & $\begin{array}{l}\text { A1A2 treatment with no } \\
\text { incentives }\end{array}$ \\
\hline Activity 1/2 - Low (A1A2-L) & 56 & $250 \mathrm{ECU}$ & $150 \mathrm{ECU}$ & $\begin{array}{l}\text { A1A2 treatment with low } \\
\text { incentives }\end{array}$ \\
\hline Activity 1/2 - High (A1A2-H) & 52 & $600 \mathrm{ECU}$ & 150 ECU & $\begin{array}{l}\text { A1A2 treatment with high } \\
\text { incentives }\end{array}$ \\
\hline
\end{tabular}


Table B2: Summary statistics (including treatments S, 20-Min, and EC)

\begin{tabular}{|c|c|c|c|}
\hline Treatment & \# of subjects ${ }^{(a)}$ & $\begin{array}{c}\text { Participation } \\
\text { rate }\end{array}$ & $\begin{array}{l}\text { Average effort } \\
\text { per minute }^{(b)}\end{array}$ \\
\hline \multicolumn{4}{|l|}{ (a) Experiment 1} \\
\hline Baseline (B) & 54 & $\begin{array}{c}0.96 \\
{[0.19]}\end{array}$ & $\begin{array}{c}4.22 \\
{[0.81]}\end{array}$ \\
\hline Baseline - Low (BL) & 50 & $\begin{array}{l}1.00 \\
{[0.00]}\end{array}$ & $\begin{array}{c}4.49 \\
{[0.56]}\end{array}$ \\
\hline Baseline - High (BH) & 52 & $\begin{array}{c}1.00 \\
{[0.00]}\end{array}$ & $\begin{array}{c}4.33 \\
{[0.86]}\end{array}$ \\
\hline \multicolumn{4}{|l|}{ (b) Experiment 2} \\
\hline Baseline (B) & 54 & $\begin{array}{c}0.96 \\
{[0.19]}\end{array}$ & $\begin{array}{c}4.22 \\
{[0.81]}\end{array}$ \\
\hline Early Departure (ED) & 50 & $\begin{array}{c}0.82 \\
{[0.39]}\end{array}$ & $\begin{array}{c}3.27 \\
{[1.56]}\end{array}$ \\
\hline Pause (P) & 56 & $\begin{array}{c}0.54 \\
{[0.50]}\end{array}$ & $\begin{array}{c}0.94 \\
{[1.12]}\end{array}$ \\
\hline Activity 1/2 (A1A2) & 53 & $\begin{array}{c}0.38 \\
{[0.49]}\end{array}$ & $\begin{array}{c}0.54 \\
{[0.88]}\end{array}$ \\
\hline Slider (S) & 53 & $\begin{array}{c}0.94 \\
{[0.23]}\end{array}$ & $\begin{array}{c}7.18 \\
{[1.92]}\end{array}$ \\
\hline 20-Minute (20-Min) & 52 & $\begin{array}{c}0.92 \\
{[0.27]}\end{array}$ & $\begin{array}{c}4.22 \\
{[0.91]}\end{array}$ \\
\hline Effort Choice (EC) & 55 & $\begin{array}{c}0.36 \\
{[0.49]}\end{array}$ & [.] \\
\hline \multicolumn{4}{|l|}{ (c) Experiment 3} \\
\hline Activity 1/2 (A1A2) & 53 & $\begin{array}{c}0.38 \\
{[0.49]}\end{array}$ & $\begin{array}{c}0.54 \\
{[0.88]}\end{array}$ \\
\hline Activity 1/2 - Low (A1A2-L) & 56 & $\begin{array}{c}0.98 \\
{[0.13]}\end{array}$ & $\begin{array}{c}2.52 \\
{[1.74]}\end{array}$ \\
\hline Activity 1/2 - High (A1A2-H) & 52 & $\begin{array}{c}0.96 \\
{[0.19]}\end{array}$ & $\begin{array}{c}3.27 \\
{[1.44]}\end{array}$ \\
\hline
\end{tabular}

Sample means given. Standard deviations in brackets.

For treatments A1A2, A1A2-L, and A1A2-H, we report the participation rate and average effort per minute in Activity 1.

(a) We discovered that nine subjects (three in treatment A1A2; one in treatment S; four in treatment 20-Min; and one in treatment EC) had previously participated in the same experiment. Hence, we drop these subjects in our analysis.

(b) We only consider the average effort per minute for those subjects who exerted a positive level of effort. 
Table B3: Regression results for Experiment 2 (including treatments S, 20-Min, and EC)

\begin{tabular}{|c|c|c|c|}
\hline Variables & $\begin{array}{c}\text { Participation =1 } \\
\text { if Effort }>0 \\
(\text { OLS })\end{array}$ & $\begin{array}{l}\text { Effort per minute } \\
\text { given Effort }>0 \\
\text { (OLS) }\end{array}$ & $\begin{array}{c}\text { Effort per minute } \\
\text { given Effort }>0 \\
\text { (Quantile) }\end{array}$ \\
\hline & $(1)$ & (2) & (3) \\
\hline Early Departure (ED) & $\begin{array}{l}-0.161^{* *} \\
(0.076)\end{array}$ & $\begin{array}{l}-0.940^{* * *} \\
(0.237)\end{array}$ & $\begin{array}{l}-0.581^{* * *} \\
(0.191)\end{array}$ \\
\hline Pause (P) & $\begin{array}{c}-0.431^{* * *} \\
(0.073)\end{array}$ & $\begin{array}{c}-3.255^{* * *} \\
(0.252)\end{array}$ & $\begin{array}{c}-4.002^{* * *} \\
(0.203)\end{array}$ \\
\hline Slider (S) & $\begin{array}{l}-0.041 \\
(0.074)\end{array}$ & & \\
\hline Effort Choice (EC) & $\begin{array}{c}-0.605^{* * *} \\
(0.074)\end{array}$ & & \\
\hline 20-Minute (20-Min) & $\begin{array}{l}-0.042 \\
(0.074)\end{array}$ & $\begin{array}{c}0.032 \\
(0.220)\end{array}$ & $\begin{array}{c}0.014 \\
(0.177)\end{array}$ \\
\hline Activity 1/2 (A1A2) & $\begin{array}{l}-0.590^{* * *} \\
(0.074)\end{array}$ & $\begin{array}{c}-3.720^{* * *} \\
(0.296)\end{array}$ & $\begin{array}{l}-4.156^{* * *} \\
(0.238)\end{array}$ \\
\hline$\%$ invested in risk task & $\begin{array}{l}-0.174^{* *} \\
(0.072)\end{array}$ & $\begin{array}{l}-0.278 \\
(0.297)\end{array}$ & $\begin{array}{c}0.096 \\
(0.239)\end{array}$ \\
\hline Age & $\begin{array}{l}-0.002 \\
(0.005)\end{array}$ & $\begin{array}{c}0.003 \\
(0.020)\end{array}$ & $\begin{array}{l}-0.008 \\
(0.016)\end{array}$ \\
\hline Female & $\begin{array}{c}0.013 \\
(0.041)\end{array}$ & $\begin{array}{l}0.342^{* *} \\
(0.167)\end{array}$ & $\begin{array}{c}0.121 \\
(0.135)\end{array}$ \\
\hline Economics major & $\begin{array}{l}-0.021 \\
(0.063)\end{array}$ & $\begin{array}{l}-0.137 \\
(0.263)\end{array}$ & $\begin{array}{l}-0.185 \\
(0.212)\end{array}$ \\
\hline Undergraduate student & $\begin{array}{c}0.087 \\
(0.136)\end{array}$ & $\begin{array}{c}0.835 \\
(0.559)\end{array}$ & $\begin{array}{l}0.773^{*} \\
(0.450)\end{array}$ \\
\hline Graduate student & $\begin{array}{c}0.146 \\
(0.128)\end{array}$ & $\begin{array}{c}0.910^{*} \\
(0.535)\end{array}$ & $\begin{array}{l}0.829^{*} \\
(0.431)\end{array}$ \\
\hline Australian & $\begin{array}{c}-0.132^{* * *} \\
(0.043)\end{array}$ & $\begin{array}{c}0.049 \\
(0.181)\end{array}$ & $\begin{array}{c}0.079 \\
(0.146)\end{array}$ \\
\hline \# previous experiments & $\begin{array}{l}-0.001 \\
(0.011)\end{array}$ & $\begin{array}{c}0.045 \\
(0.044)\end{array}$ & $\begin{array}{c}0.017 \\
(0.036)\end{array}$ \\
\hline Constant & $\begin{array}{l}1.064^{* * *} \\
(0.209)\end{array}$ & $\begin{array}{l}3.215^{* * *} \\
(0.818)\end{array}$ & $\begin{array}{l}3.556^{* * *} \\
(0.659)\end{array}$ \\
\hline Observations & 373 & 191 & 191 \\
\hline R-squared & 0.342 & 0.658 & - \\
\hline
\end{tabular}

Ordinary least squares estimates given in (1) and (2), and quantile (median) regression estimates given in (3). Standard errors in parentheses. For all regressions, treatment B is the reference treatment.

In all regressions, the controls are treatment variables and subjects' characteristics, which include the percentage of the endowment invested in the risk task, age, gender, study level at University, whether the subject is pursuing a major in economics, whether the subject is Australian, and previous experience with economic experiments.

For treatment A1A2, we consider participation and effort per minute in Activity 1.

${ }^{* * *},{ }^{* *},{ }^{*}$ denote statistical significance at the $1 \%, 5 \%$, and $10 \%$ levels, respectively. 